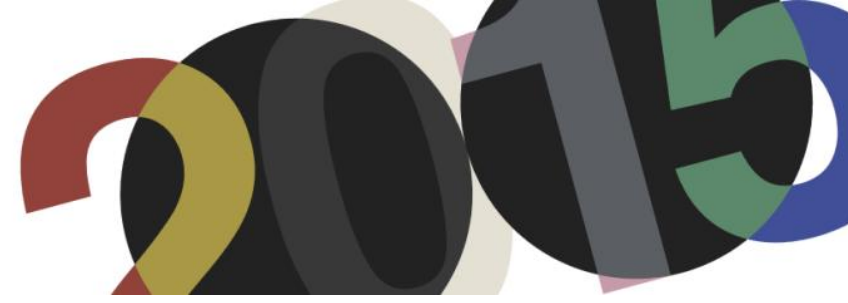

DOI: http://dx.doi.org/10.4995/LC2015.2015.1012

\title{
El espacio público en Le Corbusier. Evolución de su pensamiento y de sus estrategias formales
}

\author{
E. Alonso García
}

Escuela Técnica Superior de Arquitectura de Valladolid

\begin{abstract}
Resumen: Se analiza el papel del espacio público en diferentes obras de Le Corbusier, en sus diferentes categorías -paisaje, espacio urbano, colectivo, comunitario, de encuentro y relación, social, circulatorio, etc. - y en su implicación en las estrategias formales y espaciales. Articularemos estas reflexiones en tres apartados. El primero incidirá en la relación o identificación que se produce entre paisaje y espacio público en sus propuestas urbanísticas en las décadas de los años veinte y treinta. En el segundo apartado contrastaremos las diferencias y similitudes entre dos proyectos, UHM y Ronchamp, entendidos a veces como contradictorios pero en cuya solución proyectual resulta determinante el diseño y ubicación de los espacios colectivos de encuentro y relación de la comunidad; y ello a pesar de sus diferencias programáticas. En el tercer apartado veremos la interacción con el paisaje urbano que establece la dialéctica entre arquitectura y ciudad en dos proyectos de los últimos años, Centro de Artes Visuales Carpenter y Hospital de Venecia. Esta breve selección de edificios y proyectos, dentro de la dilatada producción de Le Corbusier, permitirá, por su adscripción temática y cronológica, establecer una adecuada perspectiva temporal en la compresión del tema y su evolución.
\end{abstract}

\begin{abstract}
It is analysed the role of the public space in different works of Le Corbusier, in their different categories landscape, urban space, collective, community, meeting and relationship, social, circulatory, etc. - and their involvement in formal and spatial strategies. We are going to distribute these reflections into three sections. The first will affect the relationship or identification that occurs between landscape and public space in its urban planning proposals in the decades of the 1920s and 1930s. In the second section, we will contrast the differences and similarities between two projects, UHM y Ronchamp, sometimes understood like contradictory but in whose design solution is determining the design and location of collective spaces of encounter and relationship of the community; and it occurs despite their functional differences. In the third section we will see the interaction with the urban landscape that the dialectic between architecture and town sets in two projects of last years, Carpenter Visuals Arts Center and Venice Hospital. This brief selection of buildings and projects, within the extensive production of Le Corbusier, will allow, by its thematic and chronological affiliation, to establish a suitable temporal perspective in the understanding of the subject and its evolution.
\end{abstract}

Palabras clave: espacio público; interrelación; paisaje; infraestructura; contexto; ciudad. Keywords: public space; interface; landscape; infrastructure; context; town.

\section{Introducción. Espacio público, paisaje y mecanización.}

El espacio público en sus diferentes categorías - espacio urbano, colectivo, comunitario, de encuentro y relación, social, circulatorio, etc. - es hoy un campo de trabajo muy presente en cualquier debate arquitectónico, cuya importancia trasciende la propia disciplina: “... lo cierto es que si se toman algunas de las obras clásicas del pensamiento urbano procuradas en las décadas de los años sesenta, setenta e incluso ochenta, el valor 'espacio público' apenas aparece o, si lo hace, ... le habrían convenido otros conceptos como "espacio social", espacio común", espacio compartido", espacio colectivo”, etc."1 y, aunque no siempre fue así, suele implicar o ir asociado a otro concepto con diferentes acepciones y paradojas, el de paisaje -paisaje natural, cultural, urbano,

\footnotetext{
${ }^{1}$ Delgado, Manuel, El espacio público como ideología. Madrid: Catarata, 2011, p. 16.
} 
interior, virtual, etc.-- La reciente exposición sobre la obra de Le Corbusier, An Atlas of Modern Landscapes ${ }^{2}$, organizada por el MOMA (2013) y que pasó por España en 2014 subrayó esta relación entre arquitectura y paisaje y la interrelación que se produce entre espacio público y espacio privado, incorporando con ello un ineludible debate ideológico en la búsqueda de las estrategias formales del proyecto.

La obra de Le Corbusier se desarrolla entre los planteamientos urbanos utopistas de finales del siglo XIX y principios del XX -Fourier, Sant'Elia, Tony Garnier- y los estudios de antropólogos, geógrafos y sociólogos cuyos textos a partir de los años de las décadas de los cincuenta y sesenta revitalizan algunas de estas cuestiones.

Estas reflexiones sobre el espacio público en Le Corbusier ilustran, por un lado, la evolución del problema en su pensamiento, el diferente protagonismo que adquiere en diversos proyectos, con escalas, programas y ubicaciones distintas, y, por otro lado, el constructo que el propio Le Corbusier va articulando en su trayectoria durante los dos primeros tercios del complejo siglo XX. Realiza muy tempranamente propuestas urbanísticas de gran escala donde el paisaje figura como el espacio público de la ciudad; son propuestas abstractas e idealizadas pero abordará también proyectos de menor tamaño con una actitud más fenoménica y contingente.

Desde el punto de vista de la fortuna crítica, en general y sobre Le Corbusier en particular, es oportuno señalar dos cuestiones: la primera se refiere al modo en que determinados logros del pensamiento quedan a veces fijados en el tiempo por más que evoluciones posteriores resulten críticas con ese momento particular y permitan elaboraciones de mayor complejidad; abordaremos a continuación las similitudes y diferencias entre estas propuestas urbanísticas realizadas entre principios y la mitad de los años veinte y sus otras propuestas de principios de los años treinta como las realizadas para Argel y Sudamérica. La segunda se refiere a la sesgada percepción de excesiva originalidad de cualquier aportación artística e intelectual por desconocimiento u ocultación de sus antecedentes. Dos responsabilidades convergen aquí para el caso que tratamos; una es el propio Le Corbusier en su afán de apropiarse de avances ajenos y rebautizarlos como nuevas invenciones ${ }^{3}$ y la otra, que afecta de modo particular al siglo XX, recae sobre la omisión de críticos y estudiosos, tendentes en ocasiones demasiado fácilmente a recrearse en la condición de invención y originalidad. En las últimas décadas, la producción de estudios atentos y rigurosos va confirmando para el caso Le Corbusier aquello que Frampton

afirmaba para la arquitectura del siglo XX, en general, en términos de "continuidad e inflexión más que en términos de originalidad como fin en sí mismo".

Le Corbusier, como tantos otros en los inicios del siglo XX, confía en la ciencia y en la técnica como remedio y salvación de tantos males que aquejan a la sociedad en general y, en particular, a las ciudades y al problema de la vivienda $^{5}$; habrán de pasar algunas décadas para comprender la carga ideológica que ambas representan. En 1941 el propio Le Corbusier recoge el sentimiento de decepción ${ }^{6}$ :

\footnotetext{
${ }^{2}$ Cohen, Jean-Louis, Le Corbusier: an atlas of modern landscapes, New York: MOMA, 2013.

${ }^{3}$ Tafuri, Manfredo. "Machine et mémoire. The City in the Work of Le Corbusier". En Brooks, H. Allen. Le Corbusier. Princeton: Princeton University Press. 1997, p. 204; a propósito de "la formulación teórica de la casa como máquina de habitar en un escrito de 1853 de Adolphe Lance”; también $c \mathrm{fr}$. Moos, Stanislaus von. Le Corbusier. Barcelona: Lumen. 1977 (1968) $1^{\text {a }}$ ed. p. 93.

${ }^{4}$ Frampton, Kenneth. "Rappel à l'Ordre: The Case for the Tectonic". En Frampton, Kenneth, Labour, work and architecture. Collected Essays on Architecture and Design. New York: Phaidon, 1987. p. 92.

${ }^{5}$ Torres Cueco, Jorge. Le Corbusier: visiones de la técnica en cinco tiempos. Barcelona: Fundación Caja de Arquitectos. 2004.

${ }^{6}$ Esta reflexión de Le Corbusier aparece en el libro Sur les Quatres Routes de 1941 y encabeza el artículo de Frampton, Kenneth "The Other Le Corbusier: Primitive Form and the Linear City, 1929-52". En Frampton, Kenneth, op. cit., p. 219.
} 
"La sociedad contemporánea sufre una devastadora enfermedad. La Mecanización, que debería haber sido un remedio para todos sus males, ha sido desplazada. Nos permitimos derramar (despreciar, desaprovechar) nuestros tradicionales modos de vida, siendo imposible llegar a un acuerdo. A pesar de milagros aislados, la era de la máquina no ha conseguido todavía sus avances. No ha sido capaz de conseguir sus propios retos ni aprendió a saltar en el vacío y establecer una nueva tradición de la felicidad humana. Así, lo que debería haber sido un laborioso recurso de la humanidad para la libertad ha llegado a ser considerado por muchos poco menos que una calamidad”.
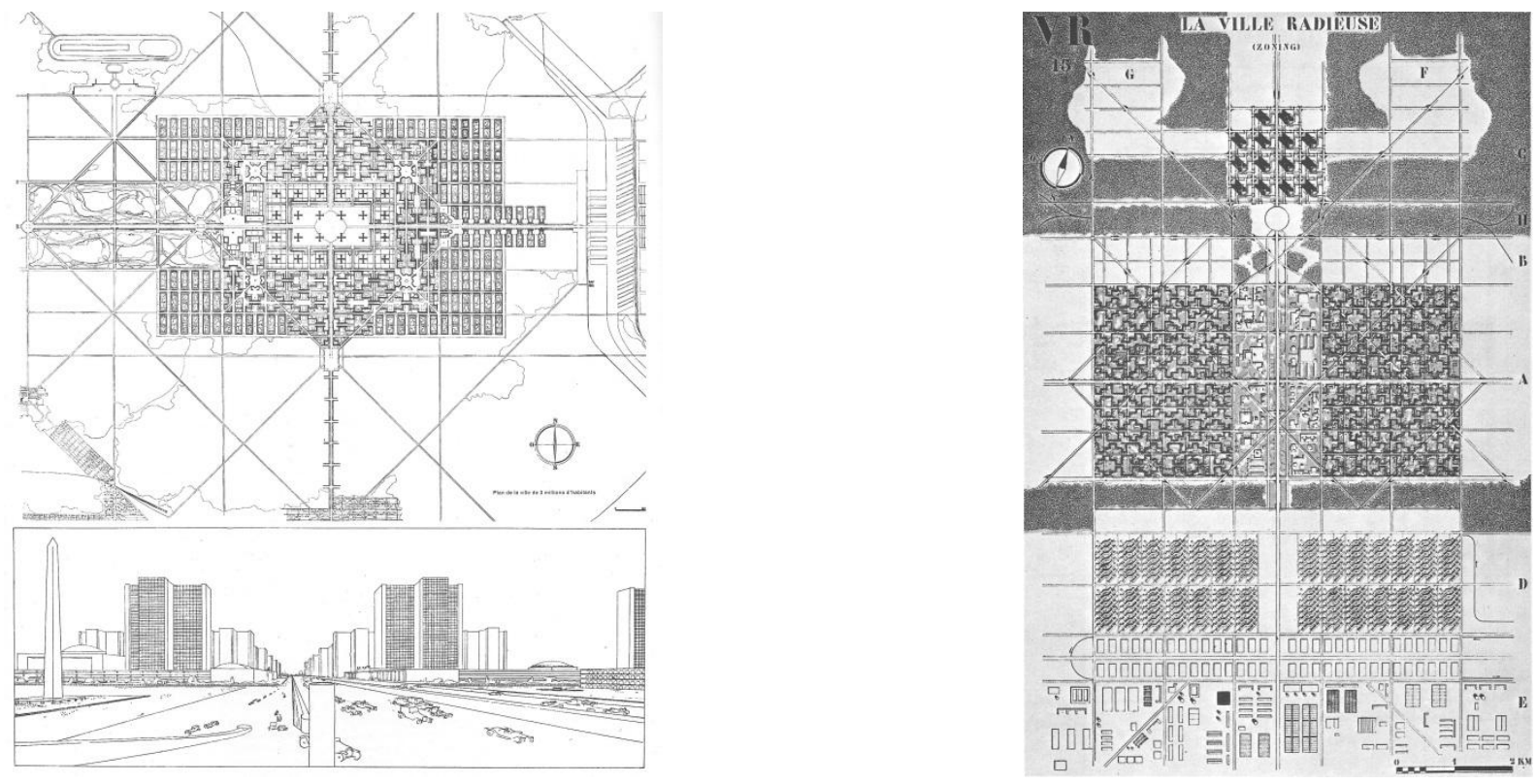

1. LC: Ville Contemporaine. Ciudad para 3 millones de habitantes, 1922. CFLC-ADAGP

2. LC: Ville Radieuse, 1925. (OFLC-ADAGP

Articularemos estas reflexiones en tres apartados. El primero incidirá en la relación o identificación que se produce entre paisaje y espacio público en sus propuestas urbanísticas en las décadas de los años veinte y treinta.. En el segundo apartado contrastaremos las diferencias y similitudes entre dos proyectos entendidos a veces como contradictorios pero en cuya solución proyectual resulta determinante el diseño y ubicación de los espacios colectivos de encuentro y relación de la comunidad; y ello a pesar de sus diferencias programáticas. En el tercer apartado veremos la interacción con el paisaje urbano que establece la dialéctica entre arquitectura y ciudad en dos proyectos de los últimos años. Esta breve selección de edificios y proyectos, dentro de la dilatada producción de Le Corbusier, permitirán, por su adscripción temática y cronológica, establecer una adecuada perspectiva temporal en la compresión del tema y su evolución. 


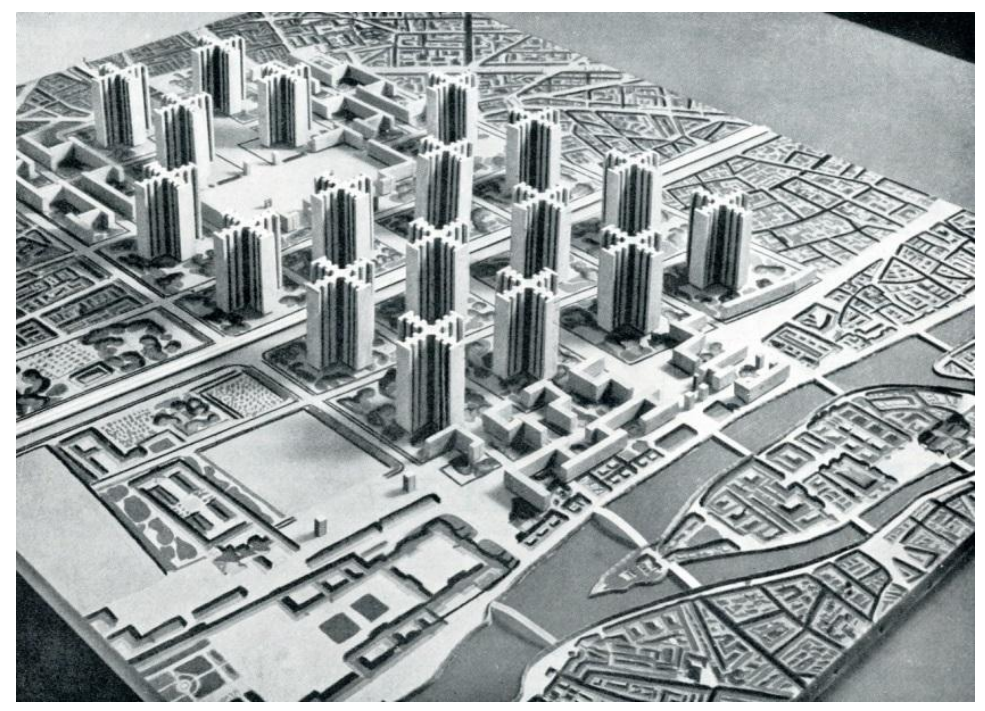

3. LC: Plan Voisin 1925. Detalle del centro (LC, Oeuvre Complète. CFLC-ADAGP)

\section{Paisaje y espacio público en las propuestas urbanas de los años 20 y 30}

Bien formado y conocedor de las teorías utopistas del siglo $\mathrm{XIX}^{7}$ sobre las teorías y propuestas urbanas para una nueva sociedad, Le Corbusier filtró pronto y reinterpretó su aprendizaje en sus propuestas urbanísticas de los años 20. Son propuestas que en su gran escala resultan necesariamente genéricas pero en donde emerge el descubrimiento de la naturaleza entendida como paisaje, con sus propias leyes compositivas y en su doble función de acoger la arquitectura, constituyéndose en su fondo natural, y para ser contemplada desde ella, dotando a la naturaleza de condición plástica y objeto experiencia artística: "la naturaleza sobre la que se asienta la ciudad de los modelos teóricos no es silvestre porque no existe ningún paisaje circundante; es un parque, una arquitectura vegetal con la que se manufactura el paisaje urbano",.

La Exposición de Artes Decorativas de 1925 consolidó la imagen vanguardista de Le Corbusier, no sólo por el propio Pabellón de l`Esprit Nouveau sino por la documentación relativa a algunas de las propuestas urbanísticas que hasta entonces había desarrollado -Plan Voisin, Ville Contemporaine-. Esta imagen quedó reforzada con la ejecución de sus obras puristas más insignes -villas Stein, Savoie,...- a finales de la década de los años veinte al tiempo que, no obstante, el propio Le Corbusier abordaba en aquellos años reflexiones bastante más críticas -las conferencias de Sudamérica, 1929, las propuestas de Argel, 1931-33, por citar algunas- con aquellos postulados que le posicionaron como uno de los máximos representantes de la modernidad mecanicista.

\footnotetext{
${ }^{7}$ Bergdoll, Berry, "París: más allá de la ciudad del siglo XX". En AV Monografías. Le Corbusier. An Altas of Landscapes. Madrid: Arquitectura Viva, 2015, 176. p. 44.

${ }^{8}$ González Cubero, Josefina. "Sesión continua: nómadas en el jardín. Ville Contemporaine y Ville Radieuse". En Monteys, Xavier. Massilia: anuario de estudios lecorbuserianos. Le Corbusier y el paisaje. Sant Cugat del Vallés, 2004. p. 75.
} 


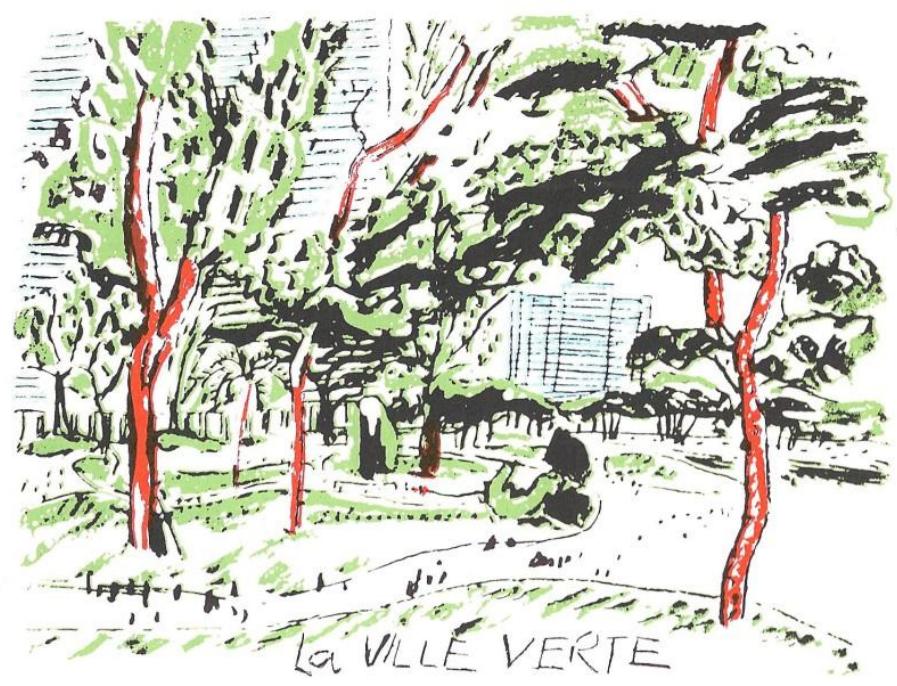

4. LC: Ville Verte (LC, Precisiones, Fig 156. CFLC-ADAGP)

Libertad, felicidad humana, salvación moral, etc., son términos y aspiraciones que el arquitecto ha recogido de los utopistas del siglo XIX y que están presentes en sus investigaciones sobre el problema de la vivienda y de la ciudad durante las primeras décadas -viviendas Dom-Ino ${ }^{9}$, Inmuebles Villas ${ }^{10}$ - en las que sobresalen dos aspectos clave, la relación de la casa con la vegetación y la naturaleza y los espacios colectivos que surgen de los mecanismos de agrupación de las viviendas. Son experiencias de pequeña escala que aluden ya a una conciencia de lo público y de las relaciones sociales cuyo marco ideal de desarrollo será en medio de un paisaje natural y lejos de los centros congestionados de la ciudad industrial.

\subsection{Paisajes habitados: la ciudad en el parque.}

$\mathrm{Al}$ abordar escalas mayores como el diseño de la Ville Contemporaine, una Ciudad para tres millones de habitantes, el paisaje natural, el parque, es el gran espacio público, la alfombra de verdor ${ }^{l 1}$, en cuyos dominios se insertan los edificios, a partir del cual se despliegan en sus diferentes escalas los diversos espacios públicos, colectivos, comunitarios, de encuentro y relación junto a la diversidad de tipologías edificatorias. Casa y ciudad insertadas en la naturaleza. Este protagonismo del paisaje natural en su relación con la arquitectura es la aportación significativa de Le Corbusier al proyecto de la ciudad contemporánea que recoge de la tradición pintoresca del siglo XIX , que le es transmitida en primera instancia por L`Eplattenier, su profesor en La Chauxde-Fonds ${ }^{12}$.

\footnotetext{
${ }^{9}$ Los espacios públicos y arbolados que resultan de la ordenación zigzagueante de los bloques Dom-Ino evocan La ciudad Industrial de Tony Garnier. Moos, Stanislaus von. Le Corbusier, op. cit. pp. 58-59.

${ }^{10}$ La calle corredor elevada en los diferentes niveles de acceso a las viviendas, que aparecerá posteriormente en los Redents y en las Unités, recuerda los corredores de los falansterios de Fourier.

${ }^{11}$ Curtis, Williams. Le Corbusier. Ideas y formas. Madrid: Blume. 1986. p. 61.

12 Ábalos, Iñaki. Atlas pintoresco. Vol. 2: los viajes. Barcelona: GG. 2008. pp.120 y ss. Analiza las influencias en Le Corbusier de los pintorescos del siglo XIX, como Frederick Law Olmsted, cuyo Central Park le impactará especialmente en su viaje a NY en 1935, junto al Rockefeller Center.
} 


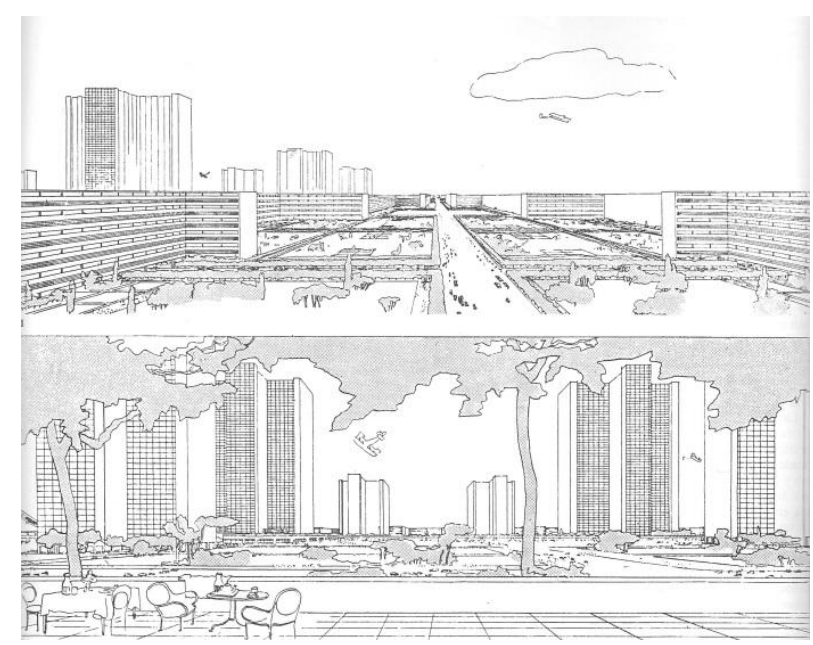

5. LC: Ville Contemporaine. Ciudad para 3 millones de habitantes, 1922. Bloques à Redents de la periferia y rascacielos del centro frente al aeropuerto (LC, Oeuvre Complète. OFLC-ADAGP)

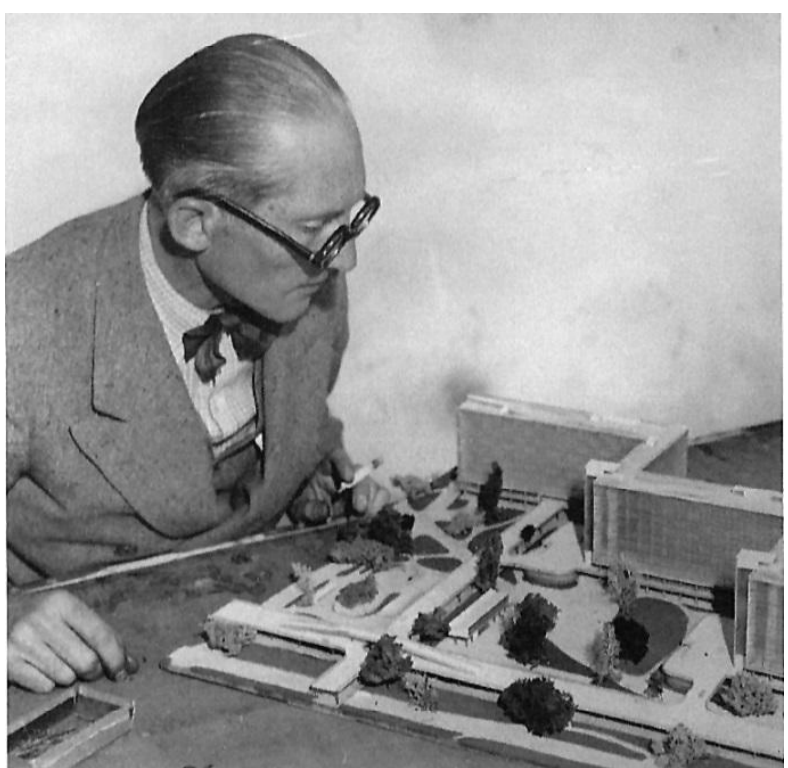

6. LC: ante la maqueta de los Bloques à Redents (LC Oeuvre Compléte. (OFLC-ADAGP)

La Ville Contemporaine (1922) y su actualización posterior, la Ville Radieuse (1930-33), son sus aportaciones teóricas a partir de la crítica moderna de la ciudad congestionada, obsoleta, insalubre, heredada del siglo XIX. Junto a un predominio compositivo de la planta que recoge mecanismos geométricos de jardines de los diseñadores franceses de los siglos XVIII y XIX ${ }^{13}$, se recogen las ambiciones utopistas de la vida en la naturaleza y a través del protagonismo "de la naturaleza en la construcción del espacio público de la ciudad"14, la gran máquina de la ciudad moderna de Le Corbusier ${ }^{15}$ adopta el espacio exterior y verde como característica determinante de sus estrategias formales.

Con diferencias en su composición y en sus trazados geométricos, ambas se asemejan en su entendimiento de articular el gran jardín como un plan urbano. La Ville Contemporaine presenta un esquema centralizado y una

\footnotetext{
${ }^{13}$ González Cubero, Josefina, op. cit. pp. 72-73.

${ }^{14}$ Ábalos, Iñaki, op. cit. p.123.

${ }^{15}$ Monteys, Xavier. La gran máquina. La ciudad en Le Corbusier. Barcelona: COAC. 1996.
} 
organización concéntrica en la secuencia tipológica que, desde el centro a la periferia, distribuye rascacielos cruciformes, bloques à redents e inmuebles-villas. Estos tres elementos básicos, que son objeto de diversas experimentaciones en proyectos específicos durante aquellos años, constituyen también la base tipológica de la Ville Radieuse que organiza con una serie de bandas paralelas, diferenciadas por usos y tipologías, y cosidas por una espina central que concluye en la agrupación de los rascacielos de oficinas, configurando una composición antropomórfica.

El Plan Voisin (1925), que arrasaba buena parte del centro de París situado al norte del Sena, representa una concreción mayor con el lugar y una menor idealización que las anteriores, adecuándose al menos a la continuidad de las calles del entorno y manteneniendo dentro de su perímetro algunos edificios preexistentes. Esta mediación, que en este caso establece la corona más exterior de los inmuebles-villas en su encuentro con las edificaciones del viejo París, sería más difícil con la propuesta Ville Radieuse. No obstante, la defensa que el propio Le Corbusier hace en Buenos Aires del Plan Voisin como "máquina de finanzas: la época maquinista ha creado una mina de diamantes en el centro de París" ${ }^{\prime 6}$, deja expuestas las razones para concitar una crítica sobre el carácter de herramienta de producción de la ciudad liberal que este tipo de planes urbanísticos contiene ${ }^{17}$.

Le Corbusier proyecta para el centro de la Ville Contemporaine siete niveles de circulación superpuestos ${ }^{18}$ que albergarían, enunciados desde abajo hasta el nivel superior: estaciones de grandes líneas, recorridos de cercanías, el metro, circulación de peatones, cruces de tránsito ligero y, finalmente, el aeropuerto. Además, la superposición de niveles, con calles elevadas para el tráfico rápido de coches, permitía la continuidad ininterrumpida de tránsitos peatonales y los recorridos sinuosos a pie entre la vegetación que explicita el dibujo de la Ville Verte ${ }^{19}$. Si en la Ville Contemporaine estas calles elevadas sobre pilotis para el tráfico se limitaban a los ejes principales, en la Ville Radieuse aparecen en mayor número y complejidad.

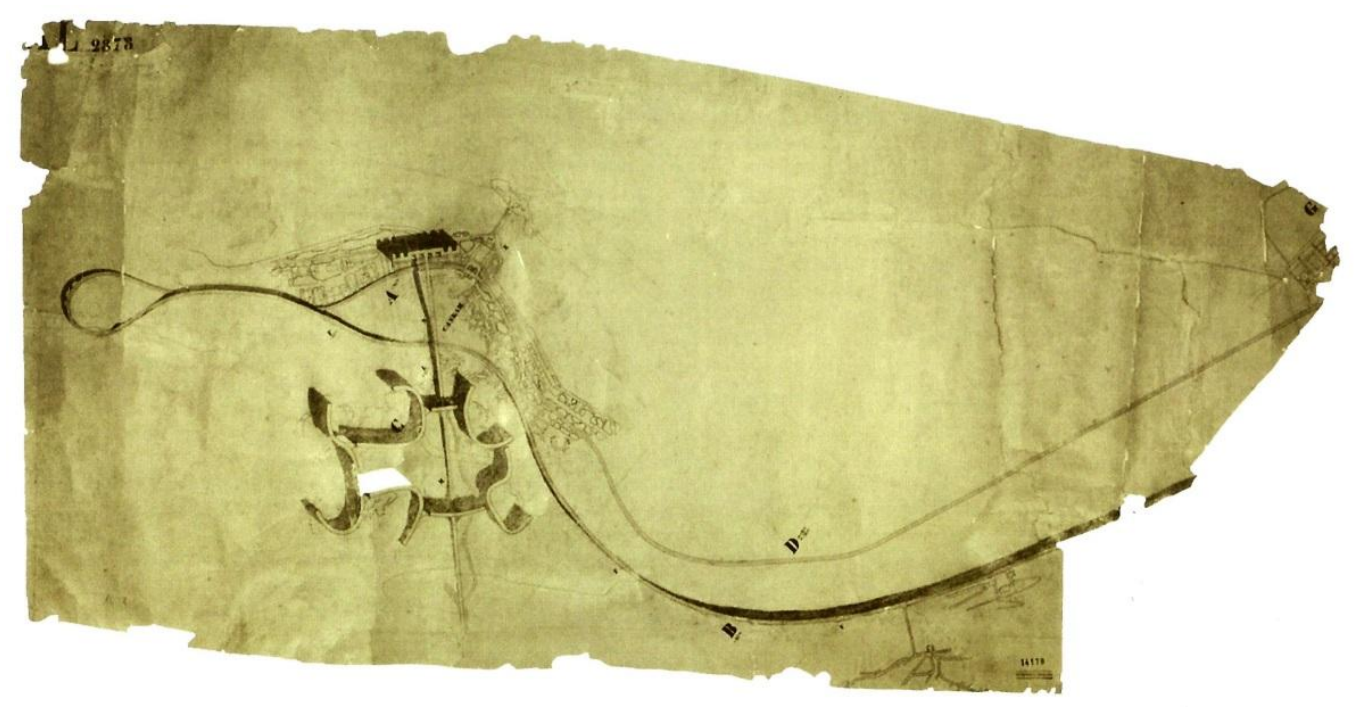

7. LC: Plan Obús para Argel (1932-34). Planta. FLC 14118. @FLC-ADAGP.

\footnotetext{
${ }^{16}$ Le Corbusier. Precisiones. Barcelona: Poseidón. $2^{\text {a }}$ ed. 1978, p. 202.

${ }^{17}$ Tafuri, Manfredo, op. cit., p. 214.

${ }^{18}$ Moos, Stanislaus von, op. cit., p. 202.

${ }^{19}$ Le Corbusier, Op. cit., p. 179.
} 


\subsection{Argel: infraestructura habitada y acústica visual.}

Las vías elevadas para el tráfico de automóviles de los modelos teóricos representan, por un lado, la reconciliación de la ciencia -el tráfico rápido sin interrupción- y la naturaleza -posibilidad de recorrer a pie, también sin interrupción, los senderos peatonales entre los árboles-; supone la convivencia de la civilización maquinista con la naturaleza ${ }^{20}$; por otra parte, estas vías rápidas elevadas vinculan el mito de la velocidad y una especial percepción del paisaje; no por casualidad, las perspectivas que muestran la contemplación del paisaje desde esta posición privilegiada mientras se conduce subrayan su predisposición al deleite en la casi total ausencia de tráfico. Es una plasmación más de las estrategias de le Corbusier en torno a la idea de una visión en movimiento $^{21}$.

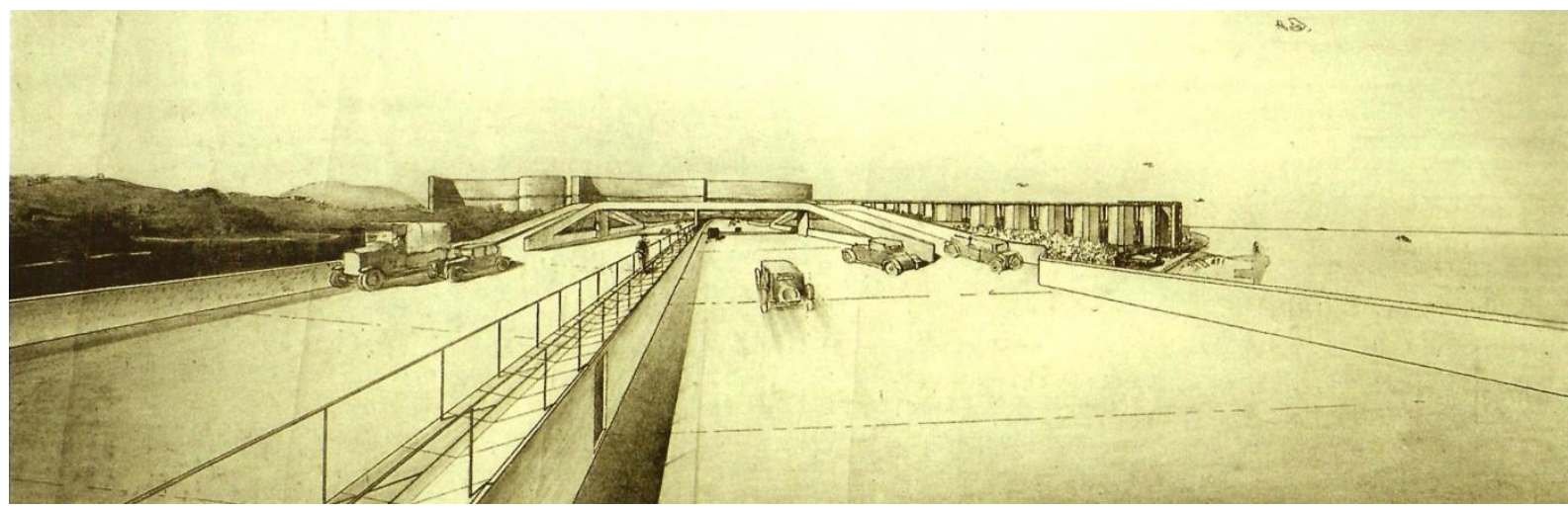

8. LC: Plan Obús para Argel (1932-34). Percepción desde el viaducto habitado mientras conducimos (Versión B. CFLC-

ADAGP)

En el proyecto Obús para Argel (1932-34) el mito de la velocidad sigue presente pero entra en juego la acusada topografía y emergen dos aspectos que anclan la propuesta al lugar con tanta radicalidad visual como significación cultural y ello se produce desde una mayor concreción y relación dialéctica con el sitio; en Argel propone construir un viaducto habitado, elevado 100 metros y bajo el cual se construirán las viviendas. Un edificio puente que recorre en paralelo la bahía, siguiendo la geometría curva de la costa. Este particular modo de responder a la topografía ya había aparecido en algunas propuestas para Sudamérica -Sao Paulo, Río de Janeiro, Montevideo- con ocasión del viaje de 1929, a la vuelta del cual escribirá durante el viaje de regreso sus Precisiones respecto a un estado actual de la arquitectura y del urbanismo. a diferencia de los modelos teóricos que hemos visto, donde los edificios residenciales construían un nuevo horizonte, ahora son esos viaductos los nuevos horizontes que referencian el lugar. La topografía provoca una reacción poética ${ }^{22}$ y, en el caso de Argel, "las curvas de la carretera evocaban el vaivén de las caderas de las mujeres y el contorno de sus cuerpos tendidos $^{23}$; el trazado sinuoso del viaducto y de los bloques à redents, situados estos sobre el promontorio de Fort L’Empereur y destinados a la vivienda de la población europea, recuerda los trazados de los desnudos de mujeres de sus dibujos y pinturas y la geometría de la caligrafía árabe. En Argel aparece también el concepto de acústica visual que Le Corbusier recuerda haber sentido por primera vez frente al Partenón en 1910 y que va a

\footnotetext{
${ }^{20}$ Picon, Antoine."Argel: ciudad, infraestructura y paisaje”. En AV Monografías, Le Corbusier. An Altas of Landscapes, op. cit. pp. 64 y ss.

${ }^{21}$ Cohen, Jean-Louis. "En defensa del paisaje”. En AV Monografías. Le Corbusier. An Altas of Landscapes, ibídem, p. 10.

${ }^{22}$ Frampton, Kenneth, "The Rise and Fall of the Radiant City: Le Corbusier 1928-1960". En Oppositions. Le Corbusier 1923-1960. 1980, 19-20. Cambridge: MIT Press, p. 3

${ }^{23}$ Picon, Antoine, op. cit., p. 66; Macleod, Mary. "Le Corbusier and Algiers" .En Oppositions, 1980, 19-20, op. cit., pp. 5585; Moos, Stanislaus von, "Le Corbusier As Painter”. En Oppositions, 1980, 19-20, ibídem, pp. 89-107.
} 
ser un argumento importante en su justificación del proyecto de Ronchamp: "El Plan Obús para Argel, inmediatamente posterior a sus vuelos americanos, será su primera gran composición de acústica visual”,24.

\section{Espacios colectivos: espacios de encuentro y relación para la comunidad.}

El juego de dualidades contrapuestas y la confrontación de fenómenos dispares es un procedimiento proyectual muy utilizado por Le Corbusier ${ }^{25}$. En la Unidad de Habitación de Marsella y en Ronchamp están también presentes pero la comparación entre ambas obras, tan cercanas en el tiempo de su ejecución y tan distantes en la fortuna crítica inicial, puede resultar estimulante. A pesar de su diferente programa, residencial y religioso, ambas atienden el desarrollo de una vida social y colectiva en un lugar determinado -recorrido, acceso, ascensión, reunión, comunicabilidad,...-. Son dos proyectos que de modo distinto privilegian los espacios colectivos de encuentro y conexión de sus respectivas comunidades.

\subsection{UHM y Ronchamp: fenómenos duales}

La Unidad de Habitación de Marsella (1947-52) y la capilla de Nôtre Dame du Haut de Ronchamp (1950-54) representan el final de una etapa, la primera, y el principio de otra, la segunda. Todavía hoy, vistas juntas, configuran una imagen ambivalente que las hace parecer cosas diversas; buena parte de la crítica asumió sin más que, abandonando las proclamas maquinistas de las décadas anteriores que prepararon la construcción de la Unidad de Habitación, Le Corbusier se sumergió en una experimentación plástica motivada por el programa religioso. Abstracción formal en la primera y empatía en la segunda expresan claramente sus diferencias y los cambios vitales.

Marsella y Ronchamp parecen dos caras contrapuestas de la reflexión sobre la relación entre técnica y arquitectura que constituye a su vez un debate permanente en la historia del arte y de la arquitectura. La primera

unidad de habitación que construyó -también la más completa de programa colectivo y más elaborada en su construcción- y la iglesia de Nôtre Dame du Haut representan dos imágenes y dos sistemas formales tan contrapuestos a priori, como sendas caras de La Gorgona que el propio Le Corbusier publicara en 1942, una figura ambivalente donde el rostro del sol, que significa vida, alude a la nueva arquitectura y la medusa Gorgona, que a quien miraba convertía en piedra, es símbolo de muerte y de la Academia ${ }^{26}$, de la dualidad entre ciencia y $\operatorname{arte}^{27}$. James Stirling expresó tempranamente en primera persona la perplejidad que gran parte de la crítica experimentó ante la dualidad contrapuesta que el propio Le Corbusier asumió al concluir dos obras casi en el mismo tiempo como Ronchamp y las casas Jaoul, apenas posteriores a la finalización de la Unidad de Habitación de Marsella. Al analizar la experiencia que Le Corbusier había recorrido en su arquitectura doméstica desde la segunda década del siglo XX hasta sus casas más brutalistas advertía que "Le Corbusier, yendo de lo general a lo particular, ha producido una obra maestra de un orden excepcional pero completamente personal" y subraya cómo Garches y Jaoul “... representan los dos extremos de su vocabulario...” 28.

\footnotetext{
${ }^{24}$ Quetglas, Josep. "Ronchamp: un paisaje de acústica visual". En AV Monografías. Le Corbusier. An Altas of Landscapes, op. cit., p. 56.

${ }^{25}$ Menin, Sarah; Samuel, Flora. Nature and Space: Aalto and Le Corbusier. London-New York: Routledge. 2003, p. 23; Curtis, Williams. Le Corbusier, op. cit., p. 11.

${ }^{26}$ Pierrefeu, François de, Le Corbusier, La maison de l’ homme, París: Plon, 1942, p. 204. La ilustración se publicó también en el cuarto volumen de la Oeuvre complète, 1965.

${ }^{27}$ Torres Cueco, Jorge, op. cit., p. 225. cfr. Frampton, Kenneth, Le Corbusier, Madrid: Akal, 2000 (Hazan, 1997), p. 96.

${ }^{28}$ Stirling, James, De Garches a Jaoul, en AR, 1955; Stirling, James, Ronchamp. La capilla de Le Corbusier y la crisis del racionalismo, en AR, 1956.
} 

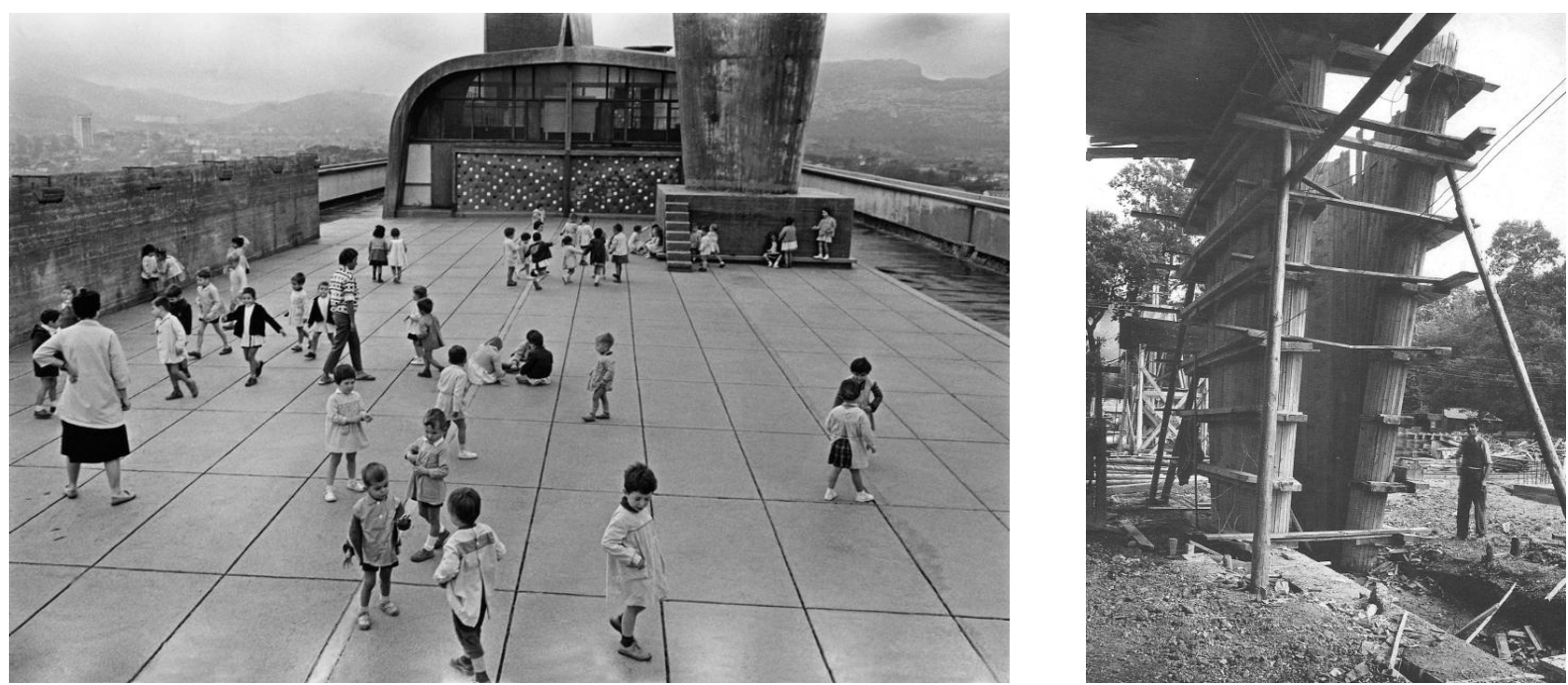

9. LC: UHM: el espacio público de la cubierta; lugar de encuentro colectivo y observatorio del paisaje. OFLC-ADAGP

\section{LC: UHM: pilotis de planta baja (FLC, L1.13.102. (FLC-ADAGP)}

No obstante esta dialéctica no es cerrada y en ambos casos se interpretan y transfieren valores de uno de ambos sistemas (maquinista y fenomenológico) en el otro. Aunque, como el propio Stirling detecta, cabe identificar claramente un cambio filosófico de actitud entre el sistema formal de la Unidad de Habitación y el de la capilla de Ronchamp, el debate contiene mayor complejidad, pues si en el contexto social es posible datar en torno a 1950 este cambio $^{29}$, también es fácil identificar ejemplos de esa actitud fenoménica con anterioridad ${ }^{30} \mathrm{y}$, a su vez, el eco de estrategias enunciadas anteriormente en las obras posteriores.

La actitud brutalista de las casas Jaoul está presente en el hormigonado en bruto de los pilotis de Marsella, cuya marcada textura de la tablazón del encofrado -que el propio arquitecto prefería frente al relamido acabado de los pilotis de Berlín- recuerda la materia de que están hechos y el trabajo artesanal de su ejecución; una actitud, que teniendo episodios anteriores, convive en Marsella con el montaje en seco de elementos prefabricados ${ }^{31}$.

\footnotetext{
${ }^{29}$ Judt, Tony, Post-guerra. Una historia de Europa desde 1945. Madrid: Santillana, 2005, p. 24.

${ }^{30}$ Frampton, Kenneth. "The other Le Corbusier: Primitive Form and the Linear City, 1929-52". En Frampton, Kenneth, Labour, work and architecture, op. cit., p. 218-225; Monteys, Xavier. "Le Plan Paralysé. Revisando los cinco puntos". En Quetglas, Josep. Massilia 2002: anuario de estudios lecorbuserianos. Barcelona: Fundación Caja de Arquitectos. 2002, pp. 141-147.

${ }^{31}$ Frampton, Kenneth, Le Corbusier, op. cit. pp. 112-146
} 


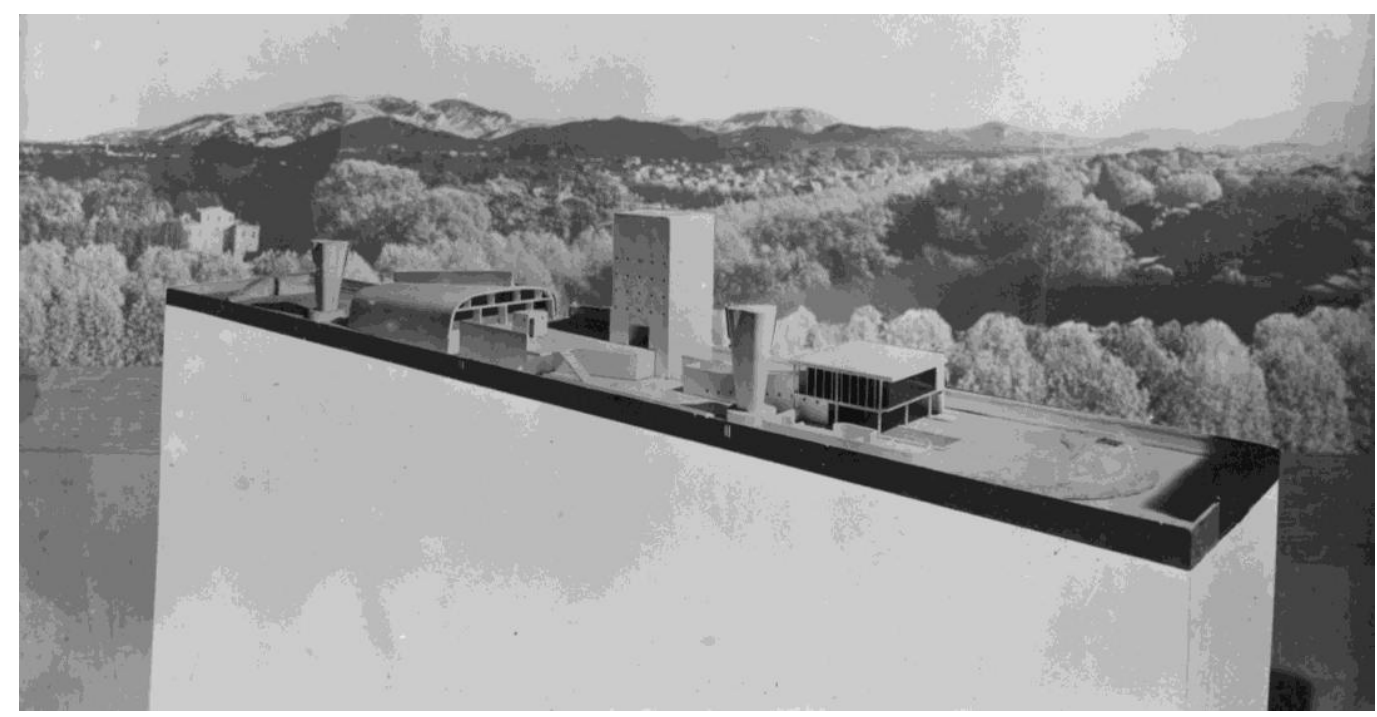

11. LC: UHM: maqueta de la cubierta (FLC, L1.12.38. (FLC-ADAGP)

\subsection{Los espacios públicos de la UHM. La soledad de las unités. Identidad y significación de la terraza comunitaria}

La imagen de jaula tridimensional del botellero es la imagen que construye la fachada del edificio como imagen alveolar, como suma de espacios o vacíos entre planos huecos que albergan la estructura y las instalaciones. El edificio consolida la imagen de esta pequeña ciudad como suma de unidades o alvéolos articulados por tres elementos de escala colectiva: la calle comercial que se ubica en niveles intermedios y los ya mencionados equipamientos y espacios de encuentro de la cubierta y de la planta baja. Su escala monumental está en consonancia con la 'grandeur conforme ${ }^{32}$ que buscaba Le Corbusier y que es el catalizador de la reinterpretación operada sobre los cinco puntos de su arquitectura. En este sentido, la Unidad de habitación de Marsella no es sólo el epígono de una época sino que se presenta como una experiencia cargada de futuro, no tanto en la traslación literal de hallazgos formales, sino en la maduración conceptual llevada a cabo sobre el papel que los aspectos técnicos van a desempeñar en la estrategia formal. Las 'unidades de habitación' conforman una ciudad vertical que alberga entre 300 y 400 familias, superponiendo sobre un desarrollo de planta común los usos privados y colectivos, circunstancia que no queda enunciada en los inicios del proyecto de Marsella pero que se alcanza en etapas sucesivas. Su carácter microurbano y acumulativo se sustancia en la autonomía formal de cada parte, significando con claridad el juego vibrante de vida -apartamentos y espacios de tránsito y relación- y azaroso juego de escalas en la combinación de usos y medidas; con la excepción de la forzada inclusión de todo el programa en la volumetría prismática, cabría advertir la traslación al proyecto de una contingencia procesual que es característica notable en Ronchamp y otras obras; de hecho, frente al resto de las unidades ejecutadas, los pilotis de Marsella denotan esta cualidad fenomenológica en su geometría y materialidad, explotando la condición 'matérica' del hormigón bruto ${ }^{33}$. Esta visualización y puesta en escena del proceso de transformación de los pilotis de Marsella -al igual que en muchas de las piezas de la cubierta: gimnasio, chimeneas de

\footnotetext{
${ }^{32}$ Banham, Reyner, "Fórmulas de vivienda colectiva. La maison des hommes y la misère des villes", en Le Corbusier (II), AV,10, Madrid, 1987, pp. 24-35; Curtis, William, Le Corbusier, op. cit., pp. 162-174; Moos, Stanislaus von, Le Corbusier, op. cit. pp. 234 y ss.; Calafell, Eduard, Las unités d’habitation de Le Corbusier, Barcelona: Fundación Caja de Arquitectos, 2000, pp. 14-35

${ }^{33}$ Gargiani, Roberto, Rosellini, Anna. Béton Brut and Ineffable Space, 1940-1965. New York-Oxford: Routledge, EPFL Press, 2011, pp. 3 y ss.
} 
ventilación, las rocas junto a la piscina, etc, cuyas geometrías explotan las posibilidades plásticas de la ejecución del hormigón bruto anticipan mecanismos de proyecto que va a experimentar a partir de Ronchamp.

La terraza en la cubierta de la UHM representa, mejor que en ninguna de las otras cuatro unités construidas ${ }^{34}$, que fueron progresivamente simplificándose, la necesidad de dotar de sentido y significado a los espacios públicos de estas ciudades verticales; la fotografía de la maqueta de la terraza, con todos sus edificios y espacios comunitarios en detalle, frente al absoluto desdibujado de todos los pisos inferiores -relegados a constituir un mero basamento de realce de esos espacios públicos de la comunidad- nos parece suficientemente expresiva de la intencionalidad significante: "Se trata del lugar que Le Corbusier denominaba toit-terrasse, que alberga una serie de instalaciones destinadas al uso colectivo, a la cultura del cuerpo y del espíritu-gimnasio, solario, sala de juegos de la guardería, teatro, piscina- y cuya formalización y disposición contrasta fuertemente con la regularidad y repetición que son una constante en el cuerpo del edificio" ${ }^{35}$. La terraza que corona el edificio acoge el desplazamiento de casi todos los equipamientos que requiere la comunidad que, a excepción de una zona comercial ubicada en plantas intermedias, son deslocalizados de la habitual cota del suelo en planta baja y reubicados en la cubierta del edificio mediante una estrategia bastante frecuente en Le Corbusier, consistente en trastocar las localizaciones habituales del programa dentro del propio edificio ${ }^{36}$. Esta cota privilegiada de la cubierta se convierte en un mirador urbano sobre el paisaje, una infraestructura clave de este edificio-ciudad, a la que complementa el suelo elevado sobre pilotis que alberga las instalaciones. El uso colectivo de la cubierta estaba ya presente en los inmuebles villas de los años veinte y en los redents de la Ville Contemporaine, pero sin la fuerte carga simbólica que la estrategia formal de estos usos comunitarios le añaden.

La soledad de una única unité lastra en buena medida la idea de la ciudad en el parque, la idea del paisaje como espacio público y la posibilidad de contemplar el cruce de senderos peatonales que se despliega en la Ville Verte. Este era el planteamiento inicial de estas pequeñas ordenaciones y así sucede en el proyecto donde por primera vez aparece el tipo edificatorio de la unité, el proyecto de dieciocho unités en Némours (1934), conectadas por una red de circulaciones con geometría romboidal para adaptarse a la topografía.

\footnotetext{
${ }^{34}$ Sbriglio, Jacques. Le Corbusier: l'Unitéd habitation de Marseille. Marseille: Parenthèses, 1992.

${ }^{35}$ Sequeira, Marta. "Toit-civique. Le Corbusier y el espacio público a 50 metros del suelo". En PC: proyecto y ciudad: revista de temas de arquitectura, 2012, n 3. Cartagena: Universidad, p. 21; Sequeira, Marta. "A Concepçâo da cobertura da Unitéd`habitation de Marselha: três invariáveis". En Quetglas, Josep et altri. Massilia 2005: anuario de estudios lecorbuserianos. San Cugat del Vallés: Centre d’investigacions estétiques. 2005, pp. 132-155.

${ }^{36}$ Alonso García, Eusebio. "Estrategias alucinatorias en el último Le Corbusier". En Actas, Critic/All. Madrid: Critic/All Press. 2014, pp. 55-73.
} 


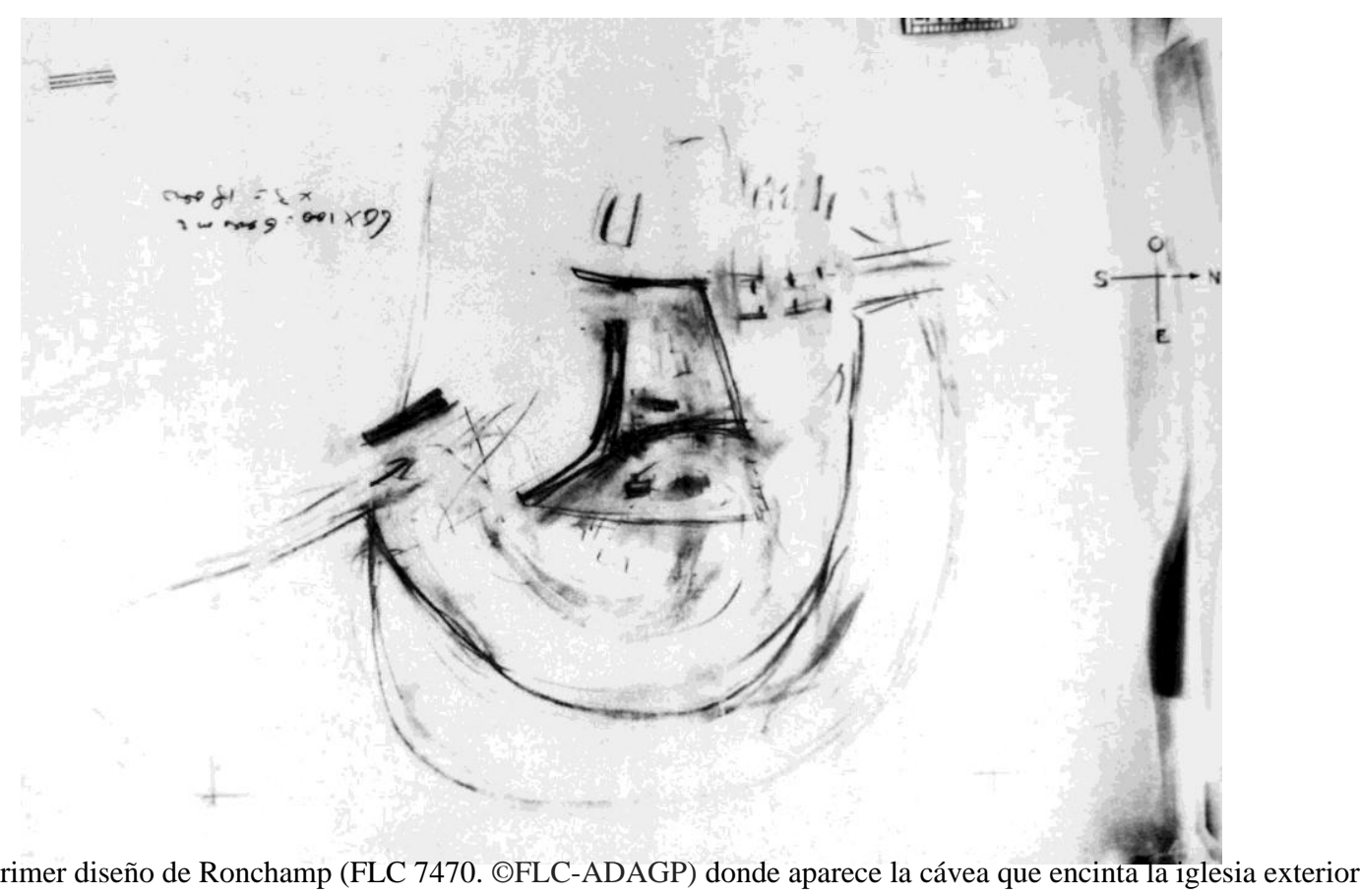

12. LC: primer diseño de Ronchamp (FLC 7470. CFLC-ADAGP) donde aparece la cávea que encinta la iglesia exterior

\subsection{La capilla de Ronchamp: identidad, memoria, significado}

La iglesia de Ronchamp protagoniza una lista de proyectos y edificios de tema religioso del que tan sólo tenía dos precedentes que no pasaron de las primeros bocetos: Le Tremblay (1929), donde una rampa exterior accede al volumen vertical y ortodoxamente prismático; la iglesia excavada en la montaña de la Sainte Baume (1948), la evocación del espacio excavado; el Convento de la Tourette (1956), donde la iglesia cierra el claustro en el lado norte y en el convento el programa de usos se superpone en diferentes niveles, ocupando los superiores las habitaciones; Firminy (1961-63 y 2003-2006); este proyecto quedó inconcluso a su muerte, en 2003 apenas estaba ejecutado parte del zócalo inferior y la iglesia ha sido recientemente concluida. Ronchamp (1950-55) es un espacio críptico y evocador, cuya forma es el resultado de un proceso altamente sensible, cuyas reglas no resultan obvias ${ }^{37}$.

Ya no es tan fácil individualizar los volúmenes platónicos que el arquitecto descubrió en la Roma clásica; estos han sufrido a lo largo del proceso de proyecto una transformación. El propio arquitecto reconoce en esos últimos años el carácter biológico de su arquitectura. Su complejidad y sus anamorfosis le acercan a los procesos formales de arquitectos barrocos como Borromini -con quien compartía también el gusto por coleccionar objects trouvés, entre ellos, conchas, caracolas-, o a la evolución formativa de los organismos biológicos que enseñó D’Arcy Thompson por primera vez en 1917 y que volvió a publicar en 1942. Alan Coulquhoun constata la "necesidad de introducir 'intención' en el proceso de diseño" ante la imposibilidad de la pura objetividad tras la entrevista con Xenakis en la que éste relata cómo en el proceso de diseño del Pabellón Philips (1958), junto a Le Corbusier (otra versión no cúbica de la boîte des mîracles): "utilizó procedimientos matemáticos para determinar la forma característica de la estructura ... el cálculo determinó la forma característica de la estructura, pero después de esto la lógica deja de actuar y la organización compositiva tiene que ser decidida

\footnotetext{
${ }^{37}$ Eardley, Anthony, Le Corbusier's Firminy Church, NY: IAUS, Rizzoli International, 1981; Teresa Trillo, Enrique de, Tránsitos de la forma, Barcelona: Fundación Caja de Arquitectos, 2009; Burriel Bielza, Luis, 2010, "El altar y la puerta en la iglesia parroquial de Saint-Pierre de Firminy-Vert”, RA n ${ }^{\circ}$ 12, junio 2010, Universidad de Navarra; Alonso García, Eusebio, "La iglesia de Firminy y la machine à émouvoir de Le Corbusier", en Actas, Porto: CEAA/Centro de Estudios Arnaldo Araújo, , 2012, pp 61-68
} 
basada en la intuición”; y concluye que "una doctrina puramente teleológica de las formas técnico-estéticas resulta insostenible ${ }^{, 38}$.

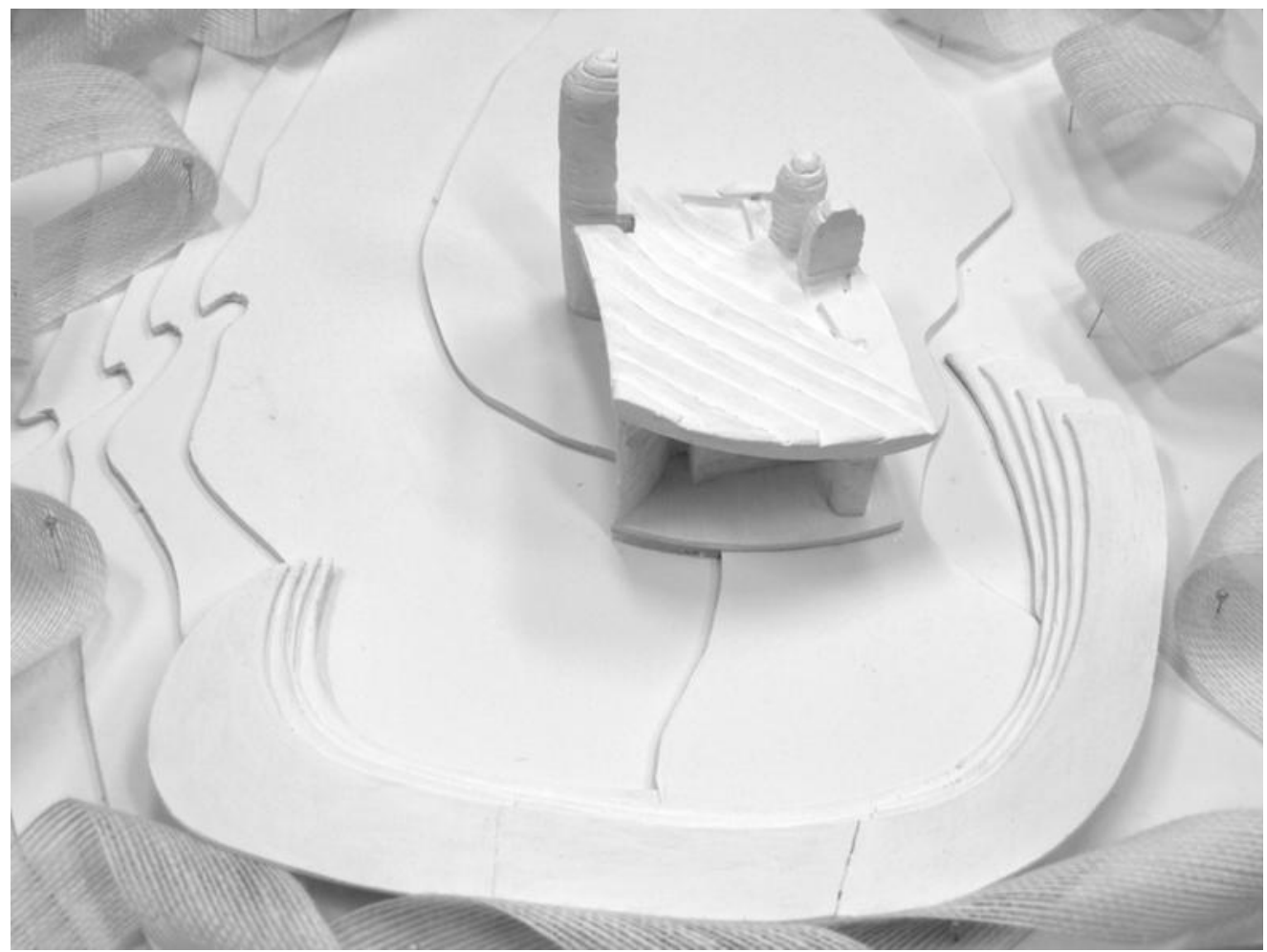

13. LC, Ronchamp. Hipótesis de maqueta según los primeros diseños de Ronchamp (CEusebio Alonso García) donde aparece la cávea que encinta la iglesia exterior.

Aldo van Eyck defendió la idea de que la arquitectura, más allá ser funcional, debía ser portadora de significado $^{39}$. Definió la arquitectura como construcción significante en una clara crítica hacia el funcionalismo e investigó en los mecanismos de accesibilidad al nivel emocional: "Van Eyck reconoció 'el lugar' en tanto que cualidad universal fundada en todas las formas de la arquitectura urbana pre-industrial, como éspacio abierto', como 'espacio hecho accesible', tanto emocional como institucional, como un espacio concreto que es conquistado por el lenguaje urbano desde el vacío neutral del espacio Newtoniano y cargado con potencial especifico de la experiencia ${ }^{, 40}$. Para Reyner Banham, la capacidad de conmover es una de las características del nuevo brutalismo; inicialmente le asignaba tres características: la legibilidad formal de la planta, clara exhibición de la estructura y valoración de los materiales por sus cualidades inherentes; posteriormente, siguiendo los proyectos de los Smithson, reemplazó el primer punto por "memorabilidad como imagen", subrayando la relevancia de la imagen por sí misma y explicaba que su valor reside en la capacidad de conmover a quien la contempla $^{41}$.

\footnotetext{
${ }^{38}$ Coulquhoun, Alan, “Tipología y método de diseño”, en Jencks, Charles, Bird, G, El significado en arquitectura. Madrid: Blume, 1975 (1969), p. 302.

${ }^{39}$ Strauven, Francis, Aldo van Eyck. The Shape of Relativity, Amsterdam: Architectura and Natura, 1998.

${ }^{40}$ Strauven, Francis, "The urban conjugation of functionalism architecture", en VV.AA., Aldo van Eyck, Amsterdam: Stichting Wonen, 1982, p. 101.

${ }^{41}$ Nernández Villalobos, Nieves, Utopías domésticas. La casa del futuro de Alison y Peter Smithson, Barcelona: Fundación Caja de Arquitectos, 2012, p. 23.
} 


\subsection{Comunicabilidad: La machine à émouvoir}

"La percepción ... funciona de una forma que es esencialmente distinta del análisis científico. La experiencia posee una naturaleza "sintética", comprende conjuntos complejos cuyos componentes, aún sin tener una relación lógica, aparecen, sin embargo, totalmente integrados. En nuestro caso es especialmente importante el amplio grupo de sistemas simbólicos conocido como arte. El arte no nos proporciona descripciones sino expresiones directas de ciertos aspectos de la realidad" ${ }^{, 42}$.

Le Corbusier apreció en sus viajes esta máquina de conmover; en el capítulo dedicado a 'arquitectura pura, creación del espíritu': “... Voici la machine à émouvoir. Nous entrons dans l'implacable de la mécanique [...] ces formes provoquent des sensations catégoriques ...Le sentiment d'une fatalité extra-humaine vous saisit. Le Parthénon, terrible machine, broie et domine ${ }^{, 43}$. La estrategia formal de Ronchamp trasciende lo razonable y constituye el paradigma de lo que le Corbusier definió como el 'espacio indecible ${ }^{44}$, algo de lo que es difícil hablar porque asistimos a una visión repentina de un proceso que ya no es mera combinatoria sino el resultado de transformaciones sucesivas que, como afirma el propio arquitecto: “... es una aventura que se desarrolla en tres tiempos: 1. integrarse en el sitio. 2. Nacimiento 'espontáneo' (después de incubación) de la totalidad de la obra, de una vez, de un golpe. 3. Lenta ejecución de los dibujos, de los diseños, de los planos y de la construcción misma y 4. Acabada la obra, la vida está implicada en la obra, totalmente encajada en una síntesis de sentimientos y de medios materiales de realización ",45.

Un diseño temprano de la planta de Ronchamp, dibujado en formato grande y en una sola sesión, conteniendo algunas correcciones, es un buen ejemplo de esto. Aunque faltan todavía piezas claves del programa como las capillas-torre, elementos fundamentales en la estabilidad del edificio, la estrategia formal está definida con claridad, conteniendo desde estos inicios las dos iglesias, la interior y la exterior de la que se ocupará en posteriores diseños y de la que finalmente no se llegará a construir la cávea que sí queda aquí recogida y aparece en numerosos diseños (un elemento éste de la cávea que acompaña a muchas de las boîte à miracles de su producción). Están ya aquí identificadas las claves de la 'acústica visual' del lugar.

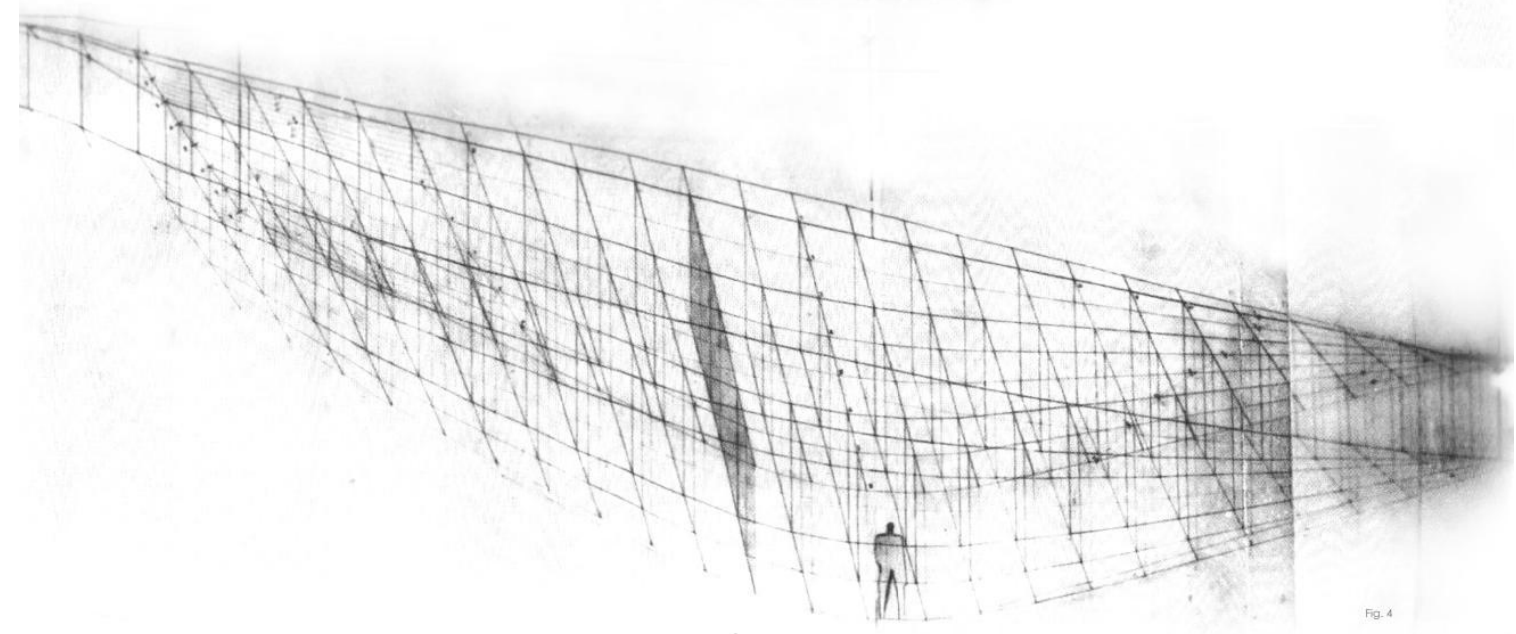

14. LC: Ronchamp. Estructura de la cubierta con las costillas de hormigón. Diseño FLC 7250. CFLC-ADAGP

\footnotetext{
${ }^{42}$ Norberg-Schulz, Christian, "El significado en arquitectura” (1966), en Jencks, Charles, op. cit., p. 242-243.

${ }^{43}$ Le Corbusier, Vers une architecture, París: Crés, 1923, p. 173.

44 "El espacio inefable": Le Corbusier, "L'espace indicible”, en L'Architecture d'Aujourd'hui, n. hors-série, “Art”, 1946, pp. 9-17

${ }^{45}$ Petit, Jean, Le livre de Ronchamp. Le Corbusier. París: Editec, 1961, p. 17.
} 
Es éste un diseño enigmático, 'como surgido de golpe', donde queda reflejada desde sus trazas iniciales la diferente función de los muros sur y este; ambos se reúnen en la esquina que habrá de recibir a los peregrinos en su acceso al sitio y cuyo encuentro con la cubierta configura una de las imágenes más crípticas y conmovedoras de la arquitectura moderna a la vez que ha generado, como advirtiera Stirling, uno de los cuestionamientos más duros a la misma. El edificio contiene todos los elementos necesarios para la liturgia, con el altar situado al este y en cuyo extremo opuesto se ubica la gran gárgola que evacua las aguas de la cubierta sobre la cisterna exterior; queda marcado así un eje este oeste que con otro transversal, que liga las dos capillas más orientales, dibuja un cruz en el pavimento interior, dispuesto con ligera pendiente hacia el altar principal, resuelto con inclinación contraria a la que adopta en el mismo eje el techo, abriendo la perspectiva y activando el terreno de la colina donde se ubica; al igual que en la iglesia exterior, la propia topografía participa en la iglesia interior.

\subsection{Ceci n'est pas une voûte}

Al igual que cuando nos aproximamos al exterior, en el interior de la iglesia 'la machine à émouvoir' actúa con eficacia y junto a la sorpresa entra en juego la memoria: reconocemos formas y mensajes, un espacio abovedado, gruesos muros y vidrieras, aunque, parafraseando a Magritte, tendríamos que decir que 'ceci n'est pas une voûte', pues lo que vemos no es una bóveda sino un gran arquitrabe con un perfil de sección en permanente variación y el muro que parece más grueso, por la geometría de sus ventanales abocinados y no coincidentes, es precisamente el muro más ligero de toda la construcción, pues es un 'muro hueco' que se construye con delgadas pantallas de hormigón armado, arriostradas horizontalmente a diferentes alturas, en concordancia con la distribución de ventanas, y sobre las que se fijaron mallas metálicas para recibir el hormigón proyectado que conforma el acabado de la pared que vemos; toda la cubierta se construyó con delgadas láminas de hormigón que exigieron un encofrado con precisión puntual para cada caso pero con un trabajo sistematizado. La técnica es sofisticada en su planteamiento y callada en su presentación, permitiendo 'activar' el espacio en la intención deseada.

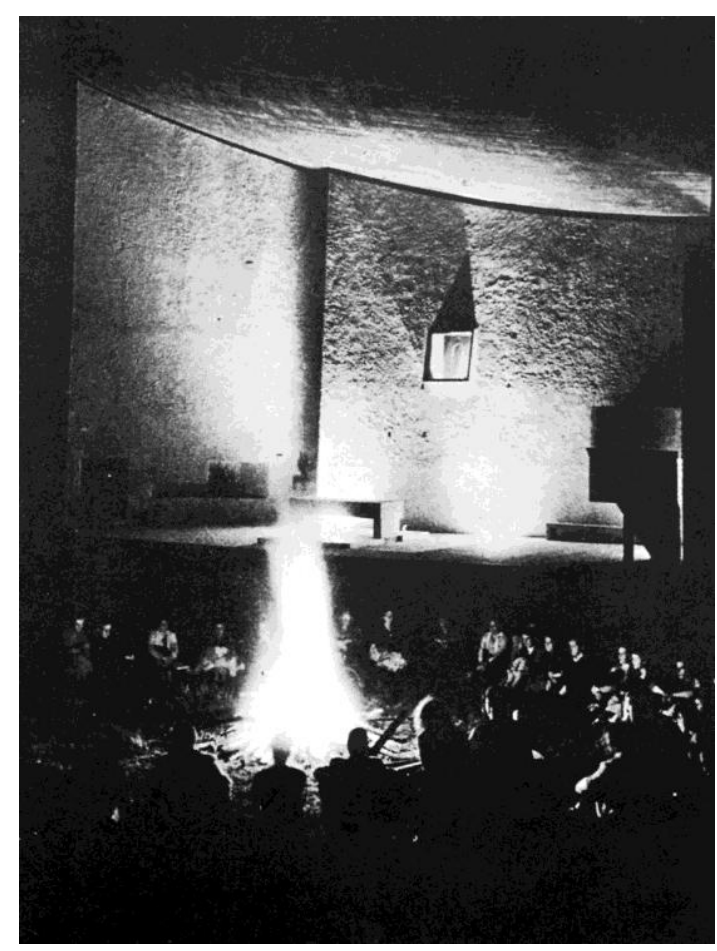

15. LC Ronchamp. Reunión de la comunidad en la explanada de la iglesia exterior (procedencia: J. Petit, Le livre de Ronchamp. (OFLC-ADAGP) 
Ronchamp es ante todo espacio interior; lo era incluso la iglesia exterior con su altar específico y su cávea envolvente $^{46}$ y nos recuerda por ello el mecanismo de la 'boîte à miracles' -no cúbica, en este caso- tal como la describió el propio Le Corbusier: “... el arquitecto puede concebir los edificios que os serán más útiles, porque posee el más alto grado de conocimiento de lo volumétrico. Puede, de hecho, crear una caja mágica que encierre todo lo que podéis desear. Desde la estancia en juego de la 'Caja de los Milagros'escena y actores se materializarán: la 'Caja de los Milagros' es un cubo; en ella se dan todas las cosas necesarias para la fabricación de los milagros, levitación, manipulación, distracción, etc. "47.

La experiencia anterior a Ronchamp fue la frustrada iglesia excavada en la montaña de la Sainte Baume y esta condición de espacio excavado y moldeado está presente en Ronchamp, no sólo por lo que respecta a la 'aparente bóveda invertida', sino por la superficie reglada de la pared del muro sur, o las capillas que alberga el espacio-estructura -en la tradición francesa del poché- de las tres torres. Todo el juego de luces, la que resbala desde lo alto de las torres, la que entra por la grieta entre los muros sur y este y la 'bóveda' es el 'juego sabio 'para activar estas sensaciones. Con obras como la iglesia de Firminy o el Pabellón Philips en la Expo de Bruselas (1958) aprendimos que la 'caja de los milagros' no tiene que ser necesariamente cúbica como si lo es, entre otras obras, en la Tourette o en el Hospital de Venecia.

Función, estructura y símbolo es un breve texto de Kenzo Tange (1966) donde aparecen estas preocupaciones, relativas a la arquitectura, al espacio urbano y a los planes urbanísticos que denotan la preocupación por estas cuestiones en la época: "Creo poder afirmar que tenemos necesidad de un concepto simbólico de la arquitectura y del espacio urbano, a fin de asegurar al hombre la significación y el valor humanos. Si hacemos corresponder una forma característica a una función característica ésta resulta perceptible de inmediato y posee su propia identidad. Desarrollando esta noción, se comprueba que a través de la forma se puede expresar no sólo una función física del espacio, sino también su significación metafísica. ... El pensamiento simbólico entra también en el proceso de estructuración. Es práctico dar una significación simbólica a la propia estructura para elaborar los planes y favorecer su comprensión por la gente"

\section{Arquitectura y ciudad. Interacciones con el paisaje urbano. De Harvard a Venecia}

Los dos últimos años de su vida Le Corbusier trabajó en el Hospital de Venecia, que finalmente no se llegará a realizar, potenciando con ello el carácter mítico y testamentario que contribuirá a ampliar la resonancia y validez de las posibilidades que el proyecto contiene, cuestión programática inherente a su propio planteamiento, pues en él se aborda no sólo la solución a determinados problemas enunciados sino la cuestión de la flexibilidad frente a la aparición de problemas futuros. Entendiendo que "Las ciudades son caleidoscópicas, metamórficas y caóticas y lo son necesariamente ${ }^{, 49}$, incorpora en la estrategia formal del proyecto la lógica formativa de la propia ciudad de Venecia. Apenas unos años antes, su intervención en la Harvard extrude la volumetría del edificio a partir a partir de interpretar cuál debe ser la relación de éste con el espacio público. En sendos casos, los espacios públicos de tránsitos y circulaciones no sólo son determinantes en la organización espacial del programa, sino

\footnotetext{
${ }^{46}$ Le Corbusier incorporó un dibujo de este espacio escénico en un diseño para un plato conmemorativo. Sobre la cualidad escénica del espacio de la iglesia exterior y su inclusión en el discurso de un "teatro en serie", cfr. QUETGLAS, Josep, "Mise en scène de Ronchamp". En RICHARD, Michel, La boîte à miracles. Le Corbusier et le théâtre. Massilia 2012. París: FLC, Editions Imbernon, 2012, pp. 108-109.

${ }^{47}$ Lámina 11, Proyecto del Museo del Siglo XX, en Le Corbusier, Oeuvre Complète, Zurich: Artemis, 1965, Volumen 7, p. 170 .

${ }^{48}$ Tange, Kenzo, "Función, estructura, símbolo", en Kultermann, Udo, Kenzo Tange 1946-1969, Barcelona: GG, 1970, p. 225; Lin, Zhongjie, KenzoTange and the Metabolism Movement, London-NY: Routledge, 2010, pp. 172 ss.

${ }^{49}$ Eyck, Aldo van, La interioridad del tiempo, en Jencks, Charles, op. cit., p. 201.
} 
que aparecen, como veíamos en el caso de la epifanía que representa el diseño FLC 7470 de Ronchamp, con clarividencia desde el inicio. Más allá de la idea de promenade architecturale -mecanismo que será negado en Venecia- es la idea de circulación y tránsito, de enlaces y conexiones lo que encuentra renovados argumentos de proyectos: "la calle como máquina de circular" había expresado años antes Le Corbusier ${ }^{50}$.

\subsection{La ciudad atraviesa la casa: el Centro de Artes Visuales Carpenter.}

Edificio con una mayor implicación urbana, que anticipa planteamientos del Hospital de Venecia; lo público y lo privado, lo individual y lo colectivo conviven simultáneamente: "En tanto que forma, lo urbano lleva un nombre; es simultaneidad ${ }^{51}$... Simultaneidad de percepciones, de acontecimientos, espacio por tanto de hipersocialización, puesto que es la forma concreta que adopta el encuentro y la reunión de todos los elementos que constituyen la vida social ${ }^{, 52}$.

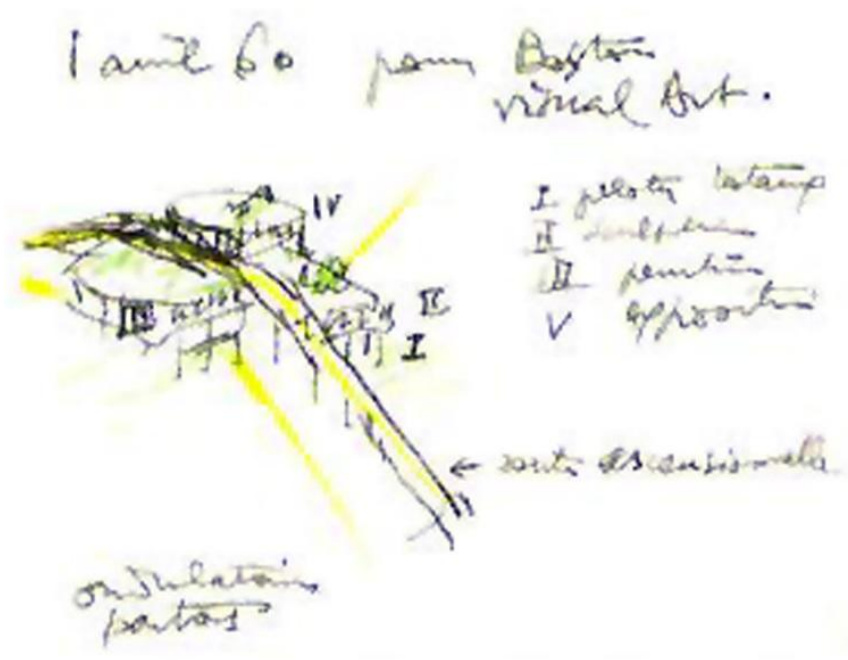

16. LC: Centro de Artes Visuales Carpenter, Universidad de Harvard (1960-63). Croquis carnet P60. OFLC-ADAGP

Sobre la base de la multitud de caminos que atravesaban diagonalmente las diferentes parcelas en el entorno de La Yarda de Harvard y sobre la idea de mantener este recorrido, al parecer existente sobre la propia parcela y con anterioridad a la construcción del centro de artes, Le Corbusier ensaya desde el inicio del proyecto esta visión de un camino que atraviesa en diagonal la parcela ${ }^{53}$; en un diseño muy temprano este recorrido parece describir un bucle sobre lo que habrá de ser el edificio, menos definido y vuelve a salir por el lado opuesto. Como en otros proyectos que hemos visto, esta intuición poética y poderosa supone un anclaje al lugar, entendido de un determinada forma o, mejor dicho, percibido de una determinada forma, pero también al programa; la idea de una calle que atraviesa el edificio satisface también el requisito de flexibilidad y el de potenciar la accesibilidad de los estudiantes de los diferentes centros del entorno a la escuela de artes, anticipándose así a la introducción de la ciudad en la casa que será tema específico en Venecia. Le Corbusier

\footnotetext{
${ }^{50}$ Torres Cueco, Jorge. "La arquitectura es la circulación”. En Torres Cueco, Jorge. Le Corbusier: mise au point. Valencia: Universidad. 2012, p.214.

${ }^{51}$ Lefebvre, Henri, El derecho a la ciudad, Barcelona: Península, 1978 (1968), p. 68.

${ }^{52}$ Lefebvre, ibidem, p. 99

${ }^{53}$ Sekler, Eduard Franz, Le Corbusier at work: the genesis of the Carpenter Center for the Visual Arts. Cambridge: Harvard University, 1978.
} 
interpreta y actualiza la relación con el espacio público de la Yarda, pero cabe reconocer también el eco de este mecanismo circulatorio en la Villa Savoya ${ }^{54}$.

Pero aquí las consecuencias son diferentes, entre otros motivos porque no se impone en ningún momento enrasar la volumetría ni por arriba ni por ningún lado; al contrario, la evolución del proyecto documenta que, definida la calle, ésta extrude el volumen que se ve paulatinamente sometido a diferentes estrategias formales que caminan en la misma dirección (desdoblamiento, escisión, deslizamiento, fragmentación); en definitiva, la calle que se eleva hasta el tercer nivel para volver a descender después de atravesar el edificio es el elemento formalmente más estable. A pesar de la pequeña dimensión, la oportunidad para desplazar el enfoque del problema arquitectónico hacia lo urbano y el espacio colectivo sitúa este proyecto en una imagen memorable gracias a esta 'calle extra' que reclamaba por aquellos años Jane Jacobs como solución a tantos problemas urbanos ${ }^{55}$.

\subsection{Hospital de Venecia: Infraestructura urbana; construir sin construir; saltando sobre la ciudad, flotando sobre el agua.}

\subsubsection{La ciudad como metáfora y analogía. Saltando sobre la ciudad y sobre el canal}

En el Hospital de Venecia, Le Corbusier asume la condición mutable del propio programa sanitario y plantea la idea de flexibilidad en su organización como mecanismo más idóneo para poder adaptarse a las situaciones diferentes. Entre estas circunstancias cambiantes, sus posibilidades de crecimiento estaban entre las más importantes, dotando al edificio de una condición de "inacabado": “... la especificidad de la sección del ático codifica genéticamente el crecimiento del Hospital... El modo en que el crecimiento queda controlado representa todavía uno de sus avances más significativos" ${ }^{, 56}$ :

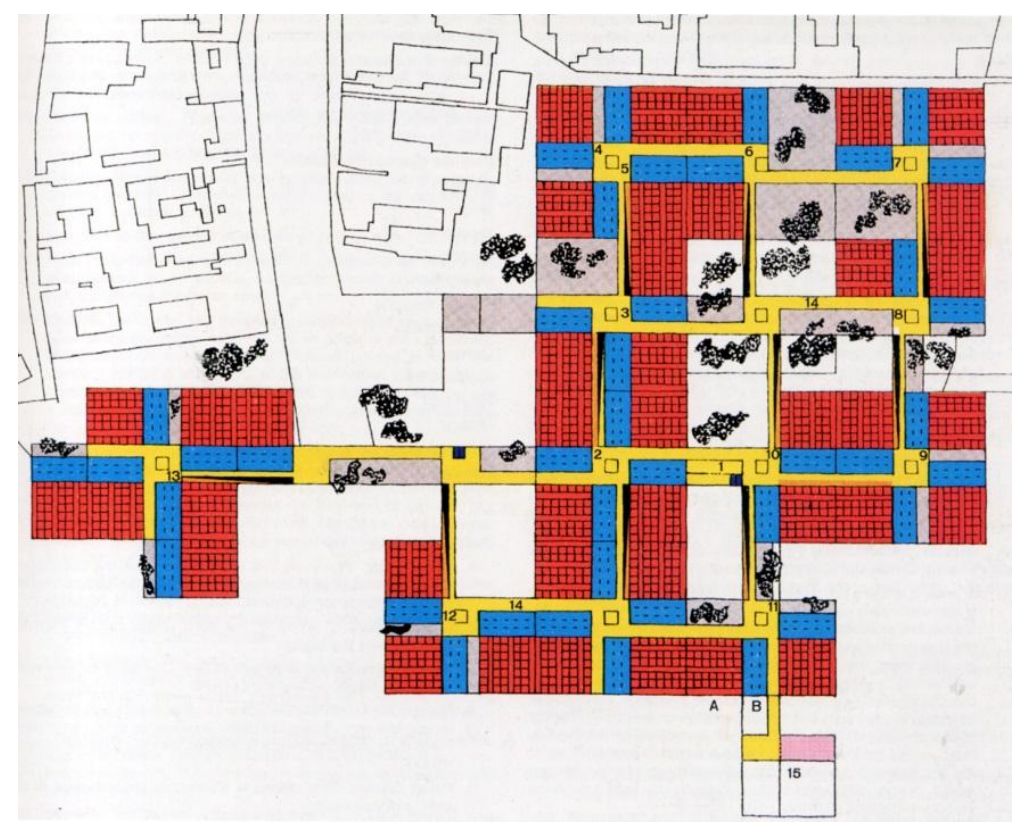

17. LC: Hospital de Venecia, 1964-65. Diseño original de LC y Jullian de la Fuente: Primer proyecto, 1964, planta 3 (procedencia: LC, Oeuvre Complète, vol. 7. OFLC-ADAGP)

\footnotetext{
${ }^{54}$ Benton, Tim. "Le Corbusier y la promenade architecturale”. En Arquitectura, 264-265. Madrid: COAM. 1987, p. 46.

${ }^{55}$ Jacobs, Jane, Muerte y vida de las grandes ciudades, Madrid: Capitán Swing Libros, 2011 (1961), p. 214.

${ }^{56}$ Sarkis, Hashim, "La paradójica promesa de la flexibilidad”. En Sarkis, Hashim, Le Corbusier's Venice Hospital and the mat building revival, Munich-London-NY: Harvard Design School, 2001.
} 
La idea de la posibilidad de crecimiento es experimentada de modos diversos en relación a cada parte distinta del casco de Venecia, de tal modo que el perímetro del hospital asume desde el proyecto las mayores condiciones de incertidumbre que cabe advertir o, lo que viene a ser lo mismo, el sistema de organización inherente y su estrategia de implantación permite resolver de forma diferente situaciones diversas; esto es, asume con naturalidad las singularidades del sistema. El Hospital de Venecia plantea un sistema sintáctico de partes iguales entre sí estableciendo múltiples enlaces en su periferia con el casco de la ciudad. El proyecto se desarrolla horizontalmente - matbuilding o edificio estera - por medio de una acumulación lógica basada en una cuidada casuística. La unidad básica del programa o 'unité de batissé, la unidad de cuidados formada por 28 camas, se repite hasta el final. La composición rotatoria de las unidades, establece conexiones y vínculos entre un pabellón y otro, mientras su desplazamiento produce la aparición de vacíos en el campo horizontal del hospital. Es la forma de esta unidad básica y el modo preciso en que son articuladas lo que acaba por configurar la forma global del edificio ${ }^{57}$.

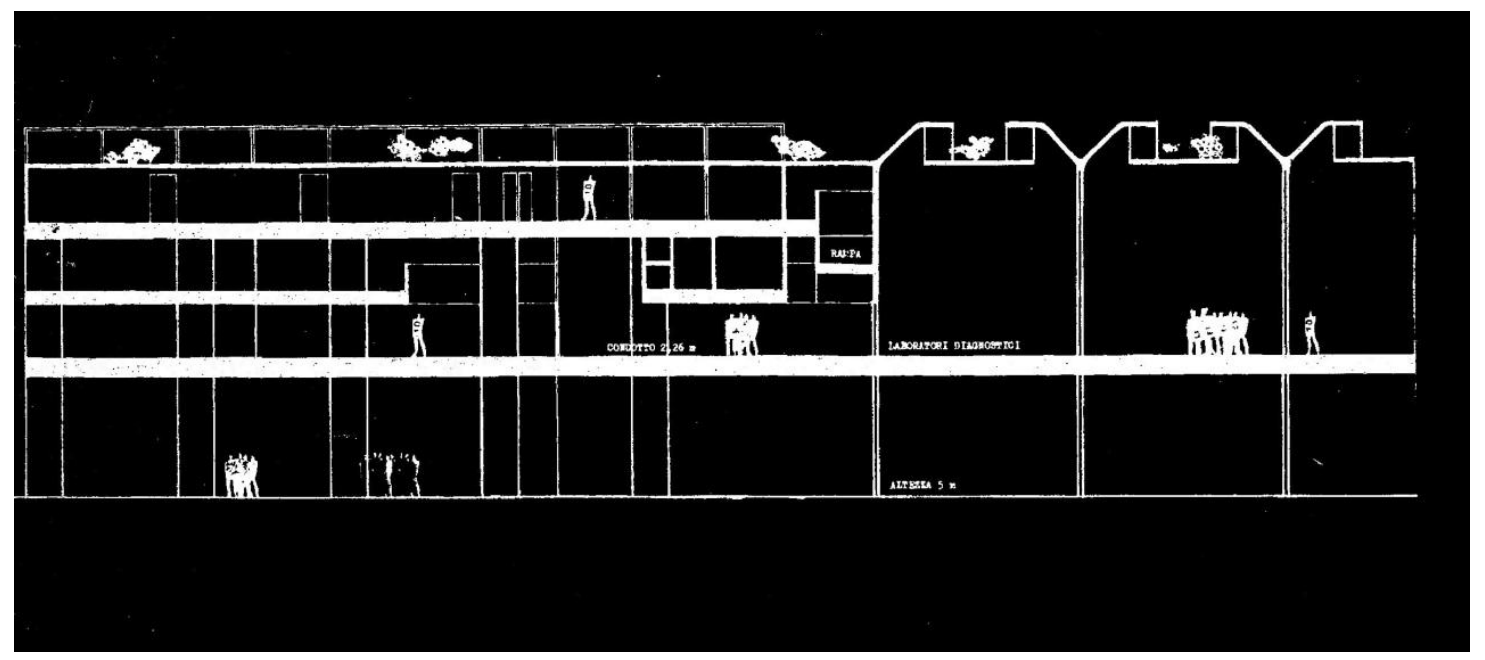

18. LC: Hospital de Venecia, 1964-65. Detalle de la sección, incluyendo laboratorios, conduits y rampas de conexión entre niveles superiores (procedencia: Hashim Sarkis, p. 4. Archivo Guillermo Jullian de la Fuente)

Si en Ronchamp resultaban determinantes los mecanismos evocadores de la memoria y el diálogo con el lugar para dotarla de significado, el Hospital de Venecia aúna en sí el hecho de ser posiblemente el proyecto más contextual de Le Corbusier y de recurrir para ello a los sistemas de crecimiento más abstractos que estaban utilizando los arquitectos del Team X, junto al abandono de la promenade architecturale, según relata el propio colaborador de Le Corbusier, Jullian de la Fuente: "Desde 1963 con el proyecto de la Olivetti empezamos a plantearnos como estructurar los diferentes espacios sin usar 'la promenade architecturalé como medio para conectarlo. El orfanato de Aldo van Eyck y sus escritos en Forum fueron una de las llamadas de atención en ese momento. La idea de un proyecto como una pequeña ciudad o parte de una ciudad fue confrontada con el proyecto del Hospital de Venecia (...). La idea de 'dual phenomena' u opuestos fue explorada y, después de mi presencia en la reunión del Team X de Royaumont, confirmado por la discusión sobre el proyecto utópico de Blom para una ciudad. Le Corbusier estuvo de acuerdo: con su proyecto de apartamentos universitarios de 1925 como modelo, añadimos nuestra capacidad para producir una conjunción de solicitaciones y variaciones que crearon la estructura, permanencia y provocación del proyecto del Hospital de Venecia de Le Corbusier "

\footnotetext{
${ }^{57}$ Cfr. Allen, Stan, “Distribuciones, Combinaciones, Campos”, en BAU, 14, 1996, pp. 68-75.

${ }^{58}$ Strauven, Francis, Aldo van Eyck's Orphanage. A Modern Monument, Amsterdam: NAI, 1996, p. 50
} 


\subsubsection{Construir sin construir}

Curiosamente en el Hospital de Venecia Le Corbusier adoptó, a favor de la flexibilidad del espacio y de la posibilidad de asumir posibles cambios internos y externos, un mecanismo basado en reglas sumamente abstractas y al mismo tiempo incorporó en su organización las claves del sistema urbano del propio lugar en el que surge el edificio: "La ciudad de Venecia está allí y yo la he continuado. No he inventado nada. He proyectado un complejo hospitalario que puede nacer, vivir y expandirse como una mano abierta: es un edificio "abierto", sin una sola fachada definitiva, en el cual se entra desde abajo, es decir, desde dentro, como en otros lugares de esta ciudad"59.

Le Corbusier traslada al edificio la lógica del contexto veneciano — calles, plazuelas, puentes, etc. - Por ello su forma es "abierta", ni cerrada ni inmutable. Su imagen no es definitiva: no sólo conceptualmente, sino que también espacialmente es posible modificarla, cambiarla, extender esta estructura, sin que por ello se altere su principio generador y su concepción arquitectónica global. Esto significa, como ha subrayado Petrilli, "construir sin construir".
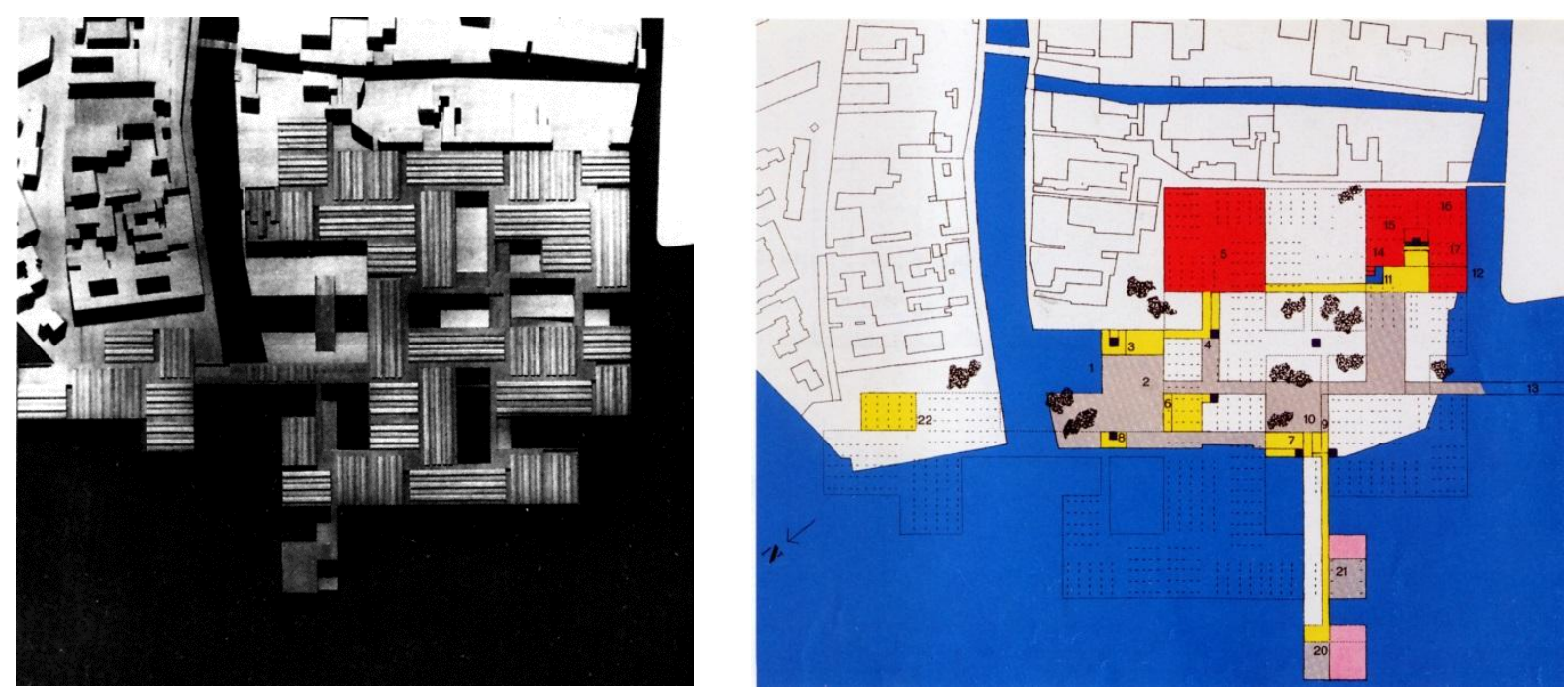

19. LC: Hospital de Venecia; maqueta del $2^{\circ}$ proyecto, 1965, vista cenital (LC, Oeuvre Complète, vol 7. (OFLC-ADAGP).

20. LC: Hospital de Venecia, 1964-65. Diseño original de LC y Jullian de la Fuente: Primer proyecto, planta 1 (LC, Oeuvre Complète. (CFLC-ADAGP)

La idea de generar un sistema de relaciones, de construir una infraestructura espacial que permita desarrollar el programa y contemplar sus variaciones a la vez que configurar espacios colectivos de relación evoca los sistemas de relaciones complejas de los “mat building”, en los que el proyecto es entendido en términos de organizaciones topológicas abiertas y variables ${ }^{60}$.

En Venecia la abstracción deriva de un entendimiento del problema en términos de infraestructura y logística. La estrategia formal del edificio, superponiendo en altura los diferentes usos, con las camas en el más elevado, se basa en la organización de las diferentes circulaciones, saltando sobre los campos, plazas y canales de la ciudad. Con el programa y la geometría diferentes de Ronchamp, las torres capillas, que inicialmente no están presentes

\footnotetext{
${ }^{59}$ Petrilli, Amedeo. Il testamento di Le Corbusier. Il progetto per l'Ospedale di Venezia, Venecia: Marsilio, 1999, p. 49.

${ }^{60}$ Cortés Vázquez de Parga, Juan Antonio, Historia de la retícula en el siglo XX. De la estructura Dom-ino a los comienzos de los años setenta, Valladolid: Universidad de Valladolid, 2013, pp.43 y ss.
} 
en el primer croquis de la iglesia y sucesivos, van progresivamente apareciendo $^{61}$, transfiriendo esta condición procesual a la propia obra a partir de una relación dialéctica y evocadora con la memoria del lugar y del programa. En Venecia esta contingencia se alimenta al proyectar un edificio con los mecanismos urbanos de la ciudad. La relación entre el edificio del hospital y el espacio público ya no es la convencional y mucho menos la relación con el suelo ${ }^{62}$. En esa década de los años 60, tal anhelo coincidirá con la reivindicación de lo público y la cualificación de espacio urbano y colectivo.

\section{A modo de conclusión: una perspectiva en el tiempo}

Estas reflexiones sobre algunas obras de Le Corbusier a partir de la idea del espacio público y del modo en que este tema incide en sus estrategias formales en torno a la arquitectura, la ciudad y el paisaje nos permite despejar una perspectiva temporal y una idea de continuidad en el modo de abordar los problemas y en el modo de concitar ideas y reacciones entre épocas, proyectos y lugares diversos. Desde la inicial vinculación a las influencias utopistas y al paisaje, de una anhelada e idealizada naturaleza, por un lado, y a la técnica, por otro, al compromiso dialéctico con el contexto urbano de Harvard o Venecia, se abre un camino de aprendizaje y confrontación con culturas y topografías que estimulan la reacción poética y la capacidad de entender el sentido y significado de los nuevos lugares. Vemos como a medida que el idealizado mito de la velocidad va sosegándose, la idea de circulación, de movimiento y de conexiones, alimenta la estrategia de proyecto con una diversidad de respuestas en las relaciones entre espacio público y espacio privado, entre arquitectura y ciudad, rica y conmovedora.

\section{Bibliografía}

ÁBALOS, Iñaki. Atlas pintoresco. Vol. 2: los viajes. Barcelona: GG. 2008.

ALLEN ,Stan, “Distribuciones, Combinaciones, Campos”, en BAU, 14, 1996.

ALONSO GARCÍA, Eusebio, La iglesia de Firminy y la machine à émouvoir de Le Corbusier, en Actas, Reapropiaciones del Movimiento Moderno. Porto: CEAA/Centro de Estudios Arnaldo Araújo, 2012.

ALONSO GARCÍA, Eusebio, Paulo Mendes Da Rocha. Constructor de horizontales en el aire, en Barcelona: DPA 30, 2014, pp. 40-49.

ALONSO GARCÍA, Eusebio, Estrategias alucinatorias en el último Le Corbusier, en Actas, Madrid: Critic/All Press, 2014, pp. 55-73.

ARENDT, Hannah, La condición humana, Barcelona: Paidós, 1993 (1958).

BANHAM, Reyner, "Fórmulas de vivienda colectiva. La maison des hommes y la misère des villes", en $L e$ Corbusier (II), AV,10, Madrid, 1987.

BERGDOLL, Berry, "París: más allá de la ciudad del siglo XX". En AV Monografías. Le Corbusier. An Altas of

\footnotetext{
61 "El acto de creación en sí mismo tiene mucha más importancia que el objeto creado y éste gana en significación en la medida en que muestra las señales del trabajo que lo ha engendrado y no está perfectamente acabado”. Así se expresaban los miembros del Grupo COBRA (1948-51), incorporados luego a la Internacional Situacionista (1957). VV.AA, Situacionistas. Arte, política, urbanismo. Barcelona: ACTAR, 1996.

“... la acción sustituyó en el siglo XVII a la contemplación, acontecimiento radical que conlleva la conciencia del carácter procesual' de cualquier experiencia, incluso la real experiencia humana... El concepto central de las dos ciencias nuevas de la Época Moderna, las naturales no menos que las históricas, es el de proceso, y la real experiencia humana subyacente es acción”. Arendt, Hannah., La condición humana. Barcelona: Paidós, 1993 (1958). p. 316

${ }^{62}$ Alonso, Eusebio, Paulo Mendes Da Rocha. Constructor de horizontales en el aire. En Barcelona: DPA 30, 2014, pp. 4049. pp. 40-49.
} 
Landscapes. Madrid: Arquitectura Viva, 2015, 176.

CALAFELL, Eduard, Las unités d'habitation de Le Corbusier, Barcelona: Fundación Caja de Arquitectos, 2000.

COHEN, Jean-Louis. "En defensa del paisaje”. En AV Monografías. Le Corbusier. An Altas of Landscapes. Madrid: Arquitectura Viva, 2015, 176.

COHEN, Jean-Louis, Le Corbusier: an atlas of modern landscapes, New York: MOMA, 2013.

CORTÉS VÁZQUEZ DE PARGA, Juan Antonio, Historia de la retícula en el siglo XX. De la estructura Domino a los comienzos de los años setenta, Valladolid: Universidad de Valladolid, 2013.

COULQUHOUN, Alan, “Tipología y método de diseño”, en JENCKS, Charles, BIRD, G, El significado en arquitectura. Madrid: Blume, 1975 (1969).

CURTIS, Williams, Le Corbusier. Ideas y formas. Madrid: Blume. 1986.

DELGADO, Manuel, El espacio público como ideología. Madrid: Catarata, 2011.

EARDLEY, Anthony, Le Corbusier's Firminy Church, NY: IAUS, Rizzoli International, 1981.

FERNÁNDEZ VILLALOBOS, Nieves, Utopías domésticas. La casa del futuro de Alison y Peter Smithson, Barcelona: Fundación Caja de Arquitectos, 2012.

FRAMPTON, Kenneth, Labour, work and architecture. Collected Essays on Architecture and Design. New York: Phaidon, 1987.

FRAMPTON, Kenneth, Le Corbusier, Akal: Madrid, 2000.

FRAMPTON, Kenneth, “The Rise and Fall of the Radiant City: Le Corbusier 1928-1960”. En Oppositions. Le Corbusier 1923-1960. 1980, 19-20. Cambridge: MIT Press, 1980.

GARGIANI, Roberto, ROSELLINI, Anna. Béton Brut and Ineffable Space, 1940-1965. New York-Oxford: Routledge, EPFL Press, 2011.

GONZÁLEZ CUBERO, Josefina. "Sesión continua: nómadas en el jardín. Ville Contemporaine y Ville Radieuse”. En Monteys, Xavier. Massilia: anuario de estudios lecorbuserianos. Le Corbusier y el paisaje. Sant Cugat del Vallés, 2004.

JACOBS, Jane, Muerte y vida de las grandes ciudades, Madrid: Capitán Swing Libros, 2011 (1961).

JENCKS, Charles, BIRD, G, El significado en arquitectura, Madrid: Blume, 1975 (1969).

JUDT, Tony, Post-guerra. Una historia de Europa desde 1945, Madrid: Santillana, 2005.

LE CORBUSIER, “L'espace indicible”, en L'Architecture d'Aujourd'hui, n. hors-série, “Art”, 1946, pp. 9-17.

LE CORBUSIER, Oeuvre Complète, Zurich: Artemis, 1965.

LE CORBUSIER. Precisiones. Barcelona: Poseidón. 2a ed. 1978 (1930).

LE CORBUSIER, Vers une architecture, París: Crés, 1923.

LEFEBVRE, Henri, El derecho a la ciudad, Barcelona: Península, 1978 (1968).

LIN, Zhongjie, Kenzo Tange and the Metabolism Movement. Urban Utopias of Modern Japan, London-NY: Routledge, 2010.

MACLEOD, Mary. "Le Corbusier and Algiers". En Oppositions. Le Corbusier 1923-1960. 1980, 19-20. Cambridge: MIT Press, 1980.

MENIN, Sarah; SAMUEL, Flora. Nature and Space: Aalto and Le Corbusier. London-New York: Routledge. 2003.

MONTEYS, Xavier. La gran máquina. La ciudad en Le Corbusier. Barcelona: COAC. 1996. 
MONTEYS, Xavier. "Le Plan Paralysé. Revisando los cinco puntos". En QUETGLAS, Josep. Massilia 2002: anuario de estudios lecorbuserianos. Barcelona: Fundación Caja de Arquitectos. 2002.

MOOS, Stanislaus von. Le Corbusier. Barcelona: Lumen. 1977 (1968) 1ª ed.

MOOS, Stanislaus von, "Le Corbusier As Painter". En Oppositions. Le Corbusier 1923-1960. 1980, 19-20. Cambridge: MIT Press, 1980.

NORBERG-SCHULZ, Christian, "El significado en arquitectura" (1966), en JENCKS, Charles, BIRD, G, El significado en arquitectura. Madrid: Blume, 1975 (1969).

O’BYRNE OROZCO, Mª Cecilia, El proyecto para el Hospital de Venecia de Le Corbusier, Tesis Doctoral, Barcelona: ETSA UPC, 2007.

PETIT, Jean, Le livre de Ronchamp. Le Corbusier, Editec, 1961.

PETRILLI, Amedeo, Il testamento di Le Corbusier. Il progetto per l'Ospedale di Venezia, Venecia: Marsilio, 1999.

PICON, Antoine."Argel: ciudad, infraestructura y paisaje”. En AV Monografias, Le Corbusier. An Altas of Landscapes, Madrid: Arquitectura Viva, 2015, 176.

PIERREFEU, François de, LE CORBUSIER, La maison de l’homme, París: Plon, 1942.

QUETGLAS, Josep. "Ronchamp: un paisaje de acústica visual". En AV Monografías. Le Corbusier. An Altas of Landscapes, Madrid: Arquitectura Viva, 2015, 176.

QUETGLAS, Josep, "Mise en scène de Ronchamp". En RICHARD, Michel, La boîte à miracles. Le Corbusier et le thêâtre. Massilia 2012. París: FLC, Editions Imbernon, 2012, pp. 98-111.

SARKIS, Hashim, "La paradójica promesa de la flexibilidad", en TRANSFER-, diciembre 2002; también Le Corbusier's Venice Hospital and the mat building revival, Munich,-London-NY: Harvard Design School, 2001.

SBRIGLIO, Jacques. Le Corbusier: l'Unitéd habitation de Marseille. Marseille: Parenthèses, 1992.

SEKLER, Eduard Franz, Le Corbusier at work: the genesis of the Carpenter Center for the Visual Arts, Cambridge: Harvard University, 1978.

SEQUEIRA, Marta. "Toit-civique. Le Corbusier y el espacio público a 50 metros del suelo". En PC: proyecto y ciudad: revista de temas de arquitectura, 2012, $\mathrm{n}^{\circ}$ 3. Cartagena: Universidad, 2012.

SEQUEIRA, Marta. "A Concepçâo da cobertura da Unitéd habitation de Marselha: três invariáveis". En QUETGLAS, Josep et altri. Massilia 2005: anuario de estudios lecorbuserianos. San Cugat del Vallés: Centre d’investigacions estétiques. 2005.

STIRLING, James, De Garches a Jaoul. Le Corbusier como arquitecto doméstico en 1927 y 1953, en Architectural Review, septiembre 1955. (Traducción en castellano en Anales de Arquitectura, Departamento de Teoría de la Arquitectura y Proyectos Arquitectónicos, Valladolid: Universidad de Valladolid, n 5, 1993/94, pp.208-213).

STIRLING, James, Ronchamp. La capilla de Le Corbusier y la crisis del racionalismo, en Architectural Review, marzo 1956. (Traducción en castellano en Anales de Arquitectura, Departamento de Teoría de la Arquitectura y Proyectos Arquitectónicos, Valladolid: Universidad de Valladolid, nº 5, 1993/94, pp. 215-219).

STRAUVEN, Francis, "The urban conjugation of functionalism architecture", en VV.AA., Aldo van Eyck, Amsterdam: Stichting Wonen, 1982.

STRAUVEN, Francis, Aldo van Eyck. The Shape of Relativity, Amsterdam: Architectura and Natura, , 1998.

STRAUVEN, Francis, Aldo van Eyck's Orphanage. A Modern Monument, Amsterdam: NAI, 1996.

TAFURI, Manfredo. "Machine et mémoire. The City in the Work of Le Corbusier". En Brooks, H. Allen. Le Corbusier. Princeton: Princeton University Press. 1997. 
TANGE, Kenzo, Función, estructura, símbolo (1966), en KULTERMANN, Udo, Kenzo Tange 1946-1969, Barcelona: GG, 1970.

TERESA TRILLO, Enrique de, Tránsitos de la forma, Barcelona: Fundación Caja de Arquitectos, 2009.

TORRES CUECO, Jorge. Le Corbusier: visiones de la técnica en cinco tiempos. Barcelona: Fundación Caja de Arquitectos. 2004.

TORRES CUECO, Jorge. "La arquitectura es la circulación”. En TORRES CUECO, Jorge. Le Corbusier: mise au point. Valencia: Universidad. 2012.

VV.AA, Situacionistas. Arte, política, urbanismo, Barcelona: ACTAR, 1996. 